\title{
Dual Labor Markets and Labor Protection in an Estimated Search and Matching Model
}

\author{
Mauricio M. Tejada* \\ ILADES - Universidad Alberto Hurtado
}

August, 2014

\begin{abstract}
Temporary contracts, as well as labor protection, have been used to reduce unemployment with the latter leading to fewer job destructions. This paper estimates a search and matching model with labor protection and dual labor markets in which the use of temporary contracts is endogenous. Chilean data is used to evaluate the role of labor protection legislation and the use of temporary contracts in unemployment, welfare, and inequality. Results indicate that both types of contracts survive in equilibrium. Temporary contracts negatively affect the frequency with which regular jobs arrive, offsetting any positive effect of firing costs on unemployment. Temporary contracts increase flexibility but welfare gains are observed only if labor protection is very stringent.
\end{abstract}

JEL Classification: C51, J4, J64

Key Words: Temporary jobs, labor protection, search models, maximum likelihood estimation, structural estimation.

${ }^{*}$ The author is grateful to Luca Flabbi, James Albrecht, and Susan Vroman for their valuable advice and suggestions. He would also like to thank Christopher Flinn, Zvi Eckstein, and Guido Menzio for their useful and constructive comments. Lastly, he would like to thank the "Subsecretaría de Previsión Social" of Chile for providing the databases of the Job Market Histories and Social Security Surveys. All the results are the author's responsibility and in no way compromise the Government of Chile. E-mail: matejada@uahurtado.cl. 


\section{Introduction}

Temporary contracts are widely used in European countries, and in the last twenty years, have proliferated in developing nations, particularly in Latin American countries (Harrison and Leamer, 1997; Heckman and Pages, 2000). They have been used to introduce flexibility in the labor market in order to reduce unemployment. However, the literature has found an ambiguous effect of temporary contracts on unemployment because these contracts not only affect the flows out of unemployment but also the flows out of employment for newly hired workers (see for example, Bentolila and Dolado, 1994; Blanchard and Landier, 2002; Güell, 2003; Aguirregabiria and Alonso-Borrego, 2009, among others). At the same time, labor protection, in the form of firing costs, has also been extensively used to reduce unemployment with the difference that this policy leads to fewer job destructions. The literature has also found that labor protection affects the job creation rate generating an ambiguous effect on unemployment (see for example, Mortensen and Pissarides, 1994, 1999b, among others) ${ }^{1}$.

A large part of the literature that analyzes both temporary contracts and labor protection policies has treated the use of temporary contracts as exogenous. Little attention has been given to the endogenous relation between the two policies. In this line of the literature, the closest paper to this research is Cahuc and Postel-Vinay (2002). However, data for some OECD and Latin American countries suggest that temporary contracts are actually used to reintroduce some flexibility when firing costs are high. In a way, this implies that employers try to avoid firing restrictions by replacing permanent with temporary workers (Harrison and Leamer, 1997). This idea is captured in Figure 1 where there is a positive relation between the degree of protection of permanent jobs and the share of temporary contracts ${ }^{2}$. Hence, the following question arises: Once the government authorizes the use of temporary contracts, are these contracts an equilibrium response of firms to introduce flexibility when firing costs are high? An interest in this endogenous relation has emerged only recently, and the related literature is still scarce (see Cao et al., 2011; Alvarez and Veracierto, 2012; Macho-Stadler et al., 2011; Paolini and de Tena, 2012).

In addition to the policy implications of temporary contracts, there are concerns regarding the use of these contracts in Latin American countries since they represent a phenomenon of job inse-

\footnotetext{
${ }^{1}$ There is an exception that occurs in the absence of perfect insurance markets where employment protection (chosen optimally) plays a role of insurance and the job creation rate is not affected (Pissarides, 2001).

${ }^{2}$ The degree of protection is captured by the index constructed by Pierre and Scarpetta (2004).
} 
curity (like informality) and can potentially have important effects on productivity and growth. In particular, they are associated with lower investment in human capital and productivity losses because the lack of attachment to the firm reduces the incentive of firms to invest in workers (Heckman and Pages, 2000). Empirically, Carpio et al. (2011), in their analysis of the Chilean labor market, find that having a temporary contract reduces the probability of receiving employer-paid training. Dolado and Stucchi (2008) also find, for the case of Spain, evidence of an impact of temporary jobs on total productivity; however, their mechanism is different. In their case, temporary contracts reduce the effort of workers if the probability of becoming a permanent worker is low. Therefore, following this line of the literature, temporary contracts generate a trade off between flexibility and productivity gains.

This paper tries to answer the following questions: Can temporary contracts emerge in equilibrium when firing costs exist in a model with search frictions? Given the trade off between flexibility and productivity, do firms find it more attractive to hire on a contingent basis? In dual labor markets (that is, with permanent and temporary contracts), are agents better off and labor market outcomes less unequal? In an effort to answer these questions, this paper extends the work presented in Mortensen and Pissarides (1994), and proposes a search and matching model with dual labor markets, in which the use of both temporary and permanent contracts is endogenously determined as part of the equilibrium. ${ }^{3}$ Furthermore, the proposed model includes firing costs in the form of severance taxes to analyze the effect of labor protection policy on the equilibrium share of both types of contracts. Finally, to capture the trade off between flexibility and productivity, the model includes, in a very simple way, a mechanism of productivity gains only for permanent jobs. The model is then structurally estimated using likelihood methods with supply side data on the Chilean labor market. To quantitatively evaluate the role of labor protection legislation and the use of temporary contracts in unemployment, welfare and inequality, the paper presents counterfactual exercises.

There are at least four reasons for working with Chilean data. First, Chile is one of the developing countries in which there was an important proliferation of contingent work arrangements in the

\footnotetext{
${ }^{3}$ In the model, the distinction between the two types of contracts is related to the degree of flexibility and not to the degree of formality (or informality) of the labor market. In this paper, both types of contracts are related to formal jobs.
} 
$1990 \mathrm{~s}^{4}$, and that period also coincides with an increase in firing costs. Second, aside from Brazil, Chile is one of the countries with the highest and more persistent levels of income inequality, not only at the regional level but also worldwide. Third, the level of informality in the Chilean labor market is one of the lowest for Latin American standards - less than $20 \%$ of employment is in the informal sector (Puentes and Contreras, 2009). Finally, for estimation purposes it is necessary to have information on labor market transitions, and the Chilean Social Protection Survey used in this paper is the only known longitudinal data for a Latin American country.

The model departs from the existing literature in two main aspects. First, this paper does not apply the commonly used definition of temporary contracts in the literature, which links this type of contract with fixed-term contracts. Instead, the analysis uses a more broad definition of temporary contracts. In particular, these contracts have a predefined duration (possibly more than 12 months), are not subject to firing costs, and are not necessarily converted to a permanent one at the end of the contract. This distinction is relevant for Latin American countries where a large proportion of the labor force is involved in agriculture and other primary activities making fixed-term contracts less relevant than per-service or seasonal jobs ${ }^{5}$. Second, it is assumed that there are two types of jobs in the market, permanent and temporary. Therefore, a productivity (and wage) distribution is associated with each type of job. This implies that some jobs are done by workers hired under a permanent contract and others are done by workers hired on a temporary basis. This assumption allows for the fitting of overlapped wage distributions, similar to the ones found in the Chilean labor market ${ }^{6}$. Indeed, as Kalleberg (2000) suggests, temporary workers earn, on average, lower wages,

\footnotetext{
${ }^{4}$ Descriptive evidence on the importance of these types of contracts in the Chilean labor market can be found in a cross-section household survey, which is representative at the national level, called the Socio-Economic Characterization Survey (CASEN). The main facts that arise from this data are: (1) temporary contracts are important even for skilled workers (they represent $35 \%$ of all jobs), (2) temporary contracts are important regardless of worker age (the share of these contracts is roughly constant across age groups), (3) temporary contracts last on average less than permanent contracts but more than 12 months (over 100 months for permanent contracts vs. close to 40 months for temporary contracts), (4) workers with permanent contracts earn more on average (almost 60\% more), but there are also workers with temporary contracts earning high wages, (5) temporary contracts have higher prevalence in some sectors, particularly among the unskilled workers (like construction, agriculture and mining).

${ }^{5}$ For example, in the case of the Chilean labor market, fixed-term contracts represent only $13 \%$ of temporary contracts, and in the case of the Mexican labor market, the proportion of fixed-term contracts is even lower, $9.3 \%$.

${ }^{6}$ However, if it is assumed that there is one productivity distribution and the firm chooses the type of contract after observing the productivity, as in Cao et al. (2011), permanent workers will always have higher productivities (and
} 
but because there is considerable heterogeneity in the wages for temporary workers, it is possible to find jobs in which temporary worker earnings are higher than those of regular employees.

Finally, in the estimation process there are observed heterogeneity controls because there is evidence that the wage gap between temporary and permanent jobs depend on education and gender (Felgueroso and De la Rica Goiricelaya, 1999). In particular, the sample used in this paper is comprised of males who are unskilled (without a college degree), since the higher wage gaps are usually found in the bottom of the distribution (Bosio, 2009).

The results obtained show that given the estimated parameters, both temporary and permanent contracts survive in equilibrium and that temporary contracts are used by firms to reintroduce flexibility when there is an increase in firing costs. There is a strong substitution effect between contracts. However, temporary contracts negatively affect the frequency with which regular jobs arrive, offsetting any positive effect of firing costs on unemployment, and generating persistent inequality. Finally, temporary contracts increase flexibility but do not make workers and firms better off (there are important productivity gains in regular jobs). Welfare gains from temporary contracts are observed only if labor protection is very stringent. This is a steady-state result and does not take into account any cushion effect on business cycles.

The paper is organized in the following manner: Section 2 presents the search and matching model and defines its steady-state equilibrium. Section 3 describes the data used in the estimations and the procedure followed to obtain the estimation sample. Section 4 presents the estimation method, discusses the identification strategy, and reports the estimation results. Section 5 contains the counterfactual and policy experiments, and, finally, Section 6 concludes.

\section{The Model}

This section describes the model setup and the determination of the steady state equilibrium. The model used in this paper is an extension of Mortensen and Pissarides (1994), which considers both temporary and permanent contracts that are endogenously determined as part of the equilibrium ${ }^{7}$.

wages) than temporary workers. As a result, it is not possible to have overlapping wages (that is, workers earning more in temporary jobs than in permanent ones).

${ }^{7}$ The model in Mortensen and Pissarides (1994), aside from being the standard tool in the literature for labor market policy analysis (Albrecht et al., 2009), studies the interaction between labor market protection and endogenous job 
This model assumes that time is continuous and that the economy is populated by infinitely lived workers, who are risk neutral and ex-ante homogenous. There is also a continuum of firms that produce their output with a fixed-coefficient technology using only labor as input. In addition, it is assumed that the labor market environment is stationary and that the search process is random. Search frictions are characterized by a matching function, which depends on the overall market tightness and the proportion of available vacancies in each type of contract. The model further assumes that there are two invariant worker-firm productivity distributions: one for each type of contract $^{8}$. Once a firm meets a worker, a match-specific productivity, conditional on the type of contract, is drawn from the relevant productivity distribution, previously mentioned, and wages are determined by Nash bargaining. Only unemployed workers search for jobs, that is, there is no on-the-job search in the model.

The main differences between permanent and temporary contracts are due to employment protection legislation and productivity gains. Permanent contracts are related to regular jobs, for which there is no specified term in the contract and there is job protection in the form of firing costs. Additionally, workers with permanent contracts are subject to idiosyncratic productivity shocks, which can be positive or negative. Positive shocks are interpreted as productivity gains ${ }^{9}$, while negative shocks can lead to a destruction of the worker-firm match, implying that permanent contracts are subject to endogenous job destruction.

On the other hand, this paper departs from the widely used definition of temporary contracts in the literature, in which these contracts are considered to have a fixed-term characteristic (see for example, Cahuc and Postel-Vinay, 2002; Cao et al., 2011) ${ }^{10}$. Instead, this paper (following the discussion from the previous section) follows Wasmer (1999), which presents a more general definition of temporary contracts. More specifically, these contracts are defined-duration contracts with contract-specific durations. This implies that these contracts can last a finite number of periods (possibly more than one) and two contracts can differ in their durations. Temporary contracts can be terminated, at no cost, either because the maximum duration expires or by a destruction shock; both destruction, which is particularly relevant for the analysis in this paper.

${ }^{8}$ This assumption allows for the fitting of cases in which productivities overlap across contracts.

${ }^{9}$ In particular, these productivity gains can be interpreted as human capital investments, which exist in this type of contract given the incentives provided by a permanent contractual relation (Heckman and Pages, 2000).

${ }^{10}$ In a fixed-term contract, as defined in the literature, the job lasts for one period and can be converted to a permanent contract upon its expiration date, at no cost. 
cases are treated as an exogenous termination. Finally, it is assumed that firms do not transform this type of contract into a permanent contract.

The introduction of firing costs, in the form of severance tax payments, has important implications on wage determination, since firing costs change the threat point in the Nash bargaining game. In particular, if a firm with a permanent contract meets a worker, then they bilaterally bargain the wage; and if the job is not created (due to a bad productivity draw) then both the worker and the firm continue the searching process without any severance tax payment. On the other hand, if a worker is currently employed with a permanent contract and he receives a productivity shock, then the worker and the firm engage in a wage renegotiation process. However, in this case the firm has to pay the severance tax if the job is destroyed; therefore, the bargaining position of the worker is better (the outside option of the firm is different in both cases). Following the same terminology as in Pissarides (2000), a newly hired worker is called an outsider worker, while a continuing employee is called an insider worker. Additionally, payroll taxes exist on both sides of the market. As in Albrecht et al. (2009), and to simplify the analysis, it is assumed that the collected taxes, both payroll and severance, are not redistributed among workers and are just thrown into the ocean.

It is important to mention that the distinction between the two types of contracts is related to the degree of flexibility and not to the degree of formality (or informality) of the labor market. Both types of contracts are related to formal jobs.

\subsection{Workers's Value Functions}

At any point in time, workers can be in any one of the following four states: unemployed, employed as a new hire with a permanent contract (indexed by $O P$, outsider permanent), a continuing employee with a permanent contract (indexed by $I P$, insider permanent), and employed as a new hire with a temporary contract (indexed by $T$ ). Let $u$ be the rate of unemployment, and $v_{P}$ and $v_{T}$ be the job vacancy rates with permanent and temporary contracts, respectively. Therefore, the total vacancy rate is $v=v_{P}+v_{T}$. If the population is normalized to 1 , then the rates at which workers and firms potentially match are $m\left(u, v_{P}\right)$ and $m\left(u, v_{T}\right)$, respectively; $m(\cdot)$ is the matching function, which is increasing in both arguments, concave and homogeneous of degree one. Defining the overall labor market tightness as $q=\frac{v_{P}+v_{T}}{u}$ and the proportion of permanent contract vacancies with respect to the total number of vacancies as $\eta=\frac{v_{P}}{v_{P}+v_{T}}$, and using the homogeneity property of the matching 
function, it is possible to write the rates at which unemployed workers meet job vacancies with permanent and temporary contracts as $\alpha_{w}^{P}=\frac{m\left[u, v_{P}\right]}{u}=m[\eta q]$ and $\alpha_{w}^{T}=\frac{m\left[u, v_{T}\right]}{u}=m[(1-\eta) q]$, respectively ${ }^{11}$. It is assumed that only unemployed workers search for a job (there is no on-the-job search).

When a worker meets a vacancy, there is a match-specific productivity. Let $F_{i}(x)$ be the invariant worker-firm productivity distribution, for $i=P, T$, from which the productivity $x$ is drawn. Not all meetings create a job because not all workers draw a high enough productivity to make the match worthwhile. Only draws higher than the reservation productivity of new hires under permanent contracts $\left(x_{O P}^{*}\right)$ or higher than the reservation productivity under temporary contracts $\left(x_{T}^{*}\right)$ end up with a job creation for each type of contract. Let $U$ be the value of unemployment, $W_{O P}(x)$ be the value of employment for a new hire under a permanent contract, and $W_{T}(x)$ be the value of employment for a worker hired under a temporary contract. Therefore, the flow value of unemployment is expressed as:

$$
r U=b+\alpha_{w}^{P} \int_{x_{O P}^{*}}^{\infty}\left\{W_{O P}(x)-U\right\} f_{P}(x) d x+\alpha_{w}^{T} \int_{x_{T}^{*}}^{\infty}\left\{W_{T}(x)-U\right\} f_{T}(x) d x
$$

While unemployed, individuals receive a utility (or disutility) $b$ interpreted as the flow income, which is equivalent to the value of leisure. At rate $\alpha_{w}^{P}$, a worker meets a vacancy with a permanent contract, and if a job is created there is a capital gain of $W_{O P}(x)-U$. Similarly, a worker meets a vacancy with a temporary contract, at rate $\alpha_{w}^{T}$, and when the job opportunity is taken there is a capital gain of $W_{T}(x)-U$.

In order to write the flow value of employment under a permanent contract, and according to the previous discussion about the effect of firing costs on wages, it is necessary to distinguish between a new hire (outsider) and a continuing employee (insider), both under permanent contracts. Let $W_{I P}(x)$ and $x_{I P}^{*}$ be the value of employment and the reservation productivity for a continuing employee under a permanent contract, respectively. The flow value of an outsider worker with a permanent contract and current productivity $x$ can then be written as:

$$
r W_{O P}(x)=w_{O P}(x)\left(1-\tau_{P}\right)+\lambda_{P} \int_{x_{I P}^{*}}^{\infty} W_{I P}\left(x^{\prime}\right) f_{P}\left(x^{\prime}\right) d x^{\prime}+\lambda_{P} F_{P}\left(x_{I P}^{*}\right) U-\lambda_{P} W_{O P}(x)
$$

\footnotetext{
${ }^{11}$ In an analogous way, the rates at which vacancies meet workers for both types of contracts can be stated as: $\alpha_{e}^{P}=\frac{m[\eta q]}{\eta q}$ and $\alpha_{e}^{P}=\frac{m[(1-\eta) q]}{(1-\eta) q}$. Alternatively: $\alpha_{w}^{P}=\eta q \alpha_{e}^{P}$ and $\alpha_{w}^{T}=(1-\eta) q \alpha_{e}^{T}$.
} 
while the flow value of an insider worker with a permanent contract can be expressed as:

$$
r W_{I P}(x)=w_{I P}(x)\left(1-\tau_{P}\right)+\lambda_{P} \int_{x_{I P}^{*}}^{\infty} W_{I P}\left(x^{\prime}\right) f_{P}\left(x^{\prime}\right) d x^{\prime}+\lambda_{P} F_{P}\left(x_{I P}^{*}\right) U-\lambda_{P} W_{I P}(x)
$$

An outsider worker with a permanent contract in a job with productivity $x$ receives an after payroll tax wage rate of $w_{O P}(x)\left(1-\tau_{P}\right)$. A productivity shock arrives at a Poisson rate $\lambda_{P}$. If the new productivity $x^{\prime}$ is above the reservation productivity $x_{I P}^{*}$, then the worker remains employed, but he is now an insider worker with a capital gain or loss of $W_{I P}\left(x^{\prime}\right)-W_{O P}(x)$. There is the possibility of productivity gains if $x^{\prime}>x$. On the contrary, if the new productivity is below the reservation productivity, then the worker becomes unemployed and the capital loss is $U-W_{O P}(x)$. If an insider worker with a permanent contract continues as an employee, then he receives an afterpayroll-tax wage rate of $w_{I P}(x)\left(1-\tau_{P}\right)$ and a capital gain or loss of $W_{I P}\left(x^{\prime}\right)-W_{I P}(x)$; but if the job is terminated, then the capital loss for the worker is $U-W_{I P}(x)$.

When a worker is employed with a temporary contract the flow value is:

$$
r W_{T}(x)=w_{T}(x)\left(1-\tau_{T}\right)+\lambda_{T} U-\lambda_{T} W_{T}(x)
$$

In this case, a worker with a temporary contract and productivity $x$, receives an after-payroll-tax wage rate of $w_{T}(x)\left(1-\tau_{T}\right)$. He loses his job at a Poisson rate $\lambda_{T}$ with a consequent capital loss of $U-W_{T}(x)$. Note that this reflects the fact that temporary contracts are not converted into permanent contracts upon their expiration dates.

\subsection{Firms' Value Functions}

$J_{O P}(x)$ and $J_{I P}(x)$ are defined as the values of a filled job for a new hire (outsider) and a continuing employee (insider), both under permanent contracts, respectively. Similarly, $J_{T}(x)$ is defined as the value of a filled job under a temporary contract. Also, let $V_{P}$ and $V_{T}$ be the values of creating a vacancy for each type of contract, permanent and temporary, respectively. Using these definitions the flow values of a filled job under a permanent contract can be written as:

$$
\begin{aligned}
r J_{O P}(x)= & x-w_{O P}(x)\left(1+\phi_{P}\right)+\lambda_{P} F_{P}\left(x_{I P}^{*}\right)\left(V_{P}-J_{O P}(x)-\Psi\right) \\
& \left.+\lambda_{P} \int_{x_{I P}^{*}}^{\infty}\left\{J_{I P}\left(x^{\prime}\right)-J_{O P}(x)\right]\right\} f_{P}\left(x^{\prime}\right) d x^{\prime}
\end{aligned}
$$


and

$$
\begin{aligned}
r J_{I P}(x)= & x-w_{I P}(x)\left(1+\phi_{P}\right)+\lambda_{P} F_{P}\left(x_{I P}^{*}\right)\left(V_{P}-J_{I P}(x)-\Psi\right) \\
& +\lambda_{P} \int_{x_{I P}^{*}}^{\infty}\left\{J_{I P}\left(x^{\prime}\right)-J_{I P}(x)\right\} f_{P}\left(x^{\prime}\right) d x^{\prime}
\end{aligned}
$$

Firms using permanent contracts receive a flow output of $x$ and pay an after payroll tax wage rate of $w_{O P}(x)\left(1+\phi_{P}\right)$ if a worker is an outsider, and $w_{I P}(x)\left(1+\phi_{P}\right)$ if he is an insider. In this setup, both the employer and the employee pay payroll taxes, making it possible to differentiate the source of the tax payment. There are two possible outcomes when there is a productivity shock. First, for any productivity greater than the reservation productivity the firm continues producing and the capital gains or losses are $J_{I P}\left(x^{\prime}\right)-J_{O P}(x)$ and $J_{I P}\left(x^{\prime}\right)-J_{I P}(x)$ for an outsider and an insider worker, respectively. Second, if the shock is sufficiently bad, that is, the new productivity has fallen below the reservation productivity, then the worker is dismissed and the firm has to pay the severance $\operatorname{tax}(\Psi)$. In this case, the capital loss, $V_{P}-J_{i}(x)-\Psi$ for $i=I P, O P$, takes into account that the firm now has an unfilled vacancy and has to pay the severance tax.

In turn, the flow value of a filled job under a temporary contract is:

$$
r J_{T}(x)=x-w_{T}(x)\left(1+\phi_{T}\right)+\lambda_{T}\left(V_{T}-J_{T}(x)\right)
$$

Firms using temporary contracts receive a flow output of $x$ and pay an after payroll tax wage rate of $w_{T}(x)\left(1+\phi_{T}\right)$. It is assumed that the payroll taxes differ with the types of contracts. When there is a termination shock the match is destroyed at no cost, generating a capital loss of $V_{T}-J_{T}(x)$ to the firm. Thus, both the worker and the firm once again engage in the search process.

Finally, the flow values of unfilled vacancies for both types of contracts are:

$$
\begin{aligned}
& r V_{P}=-k_{P}+\alpha_{e}^{P} \int_{x_{O P}^{*}}^{\infty}\left\{J_{O P}(x)-V_{P}\right\} f_{P}(x) d x \\
& r V_{T}=-k_{T}+\alpha_{e}^{T} \int_{x_{T}^{*}}^{\infty}\left\{J_{T}(x)-V_{T}\right\} f_{T}(x) d x
\end{aligned}
$$

For firms to keep the vacancies while searching, they pay a per-period fixed cost of $k_{P}$ and $k_{T}$, according to the type of contract, permanent and temporary, respectively. At rate $\alpha_{e}^{P}=\frac{\alpha_{w}^{P}}{\eta q}$, firms with a permanent contract job meet workers, and if the realized match-specific productivity is good enough (greater than the reservation productivity $x_{O P}^{*}$ of a new hire with this type of contract), then the vacancy is filled and the firms have a capital gain of $J_{O P}(x)-V_{P}$. In the case of firms with 
a temporary contract job, meetings occur at rate $\alpha_{e}^{T}=\frac{\alpha_{w}^{T}}{(1-\eta) q}$ and the capital gain for the firms is $J_{T}(x)-V_{T}$ if the job is created.

\subsection{Steady-State Equilibrium}

The steady-state condition requires that both: (1) the flow out of unemployment into jobs with permanent contracts is equal to the flow into unemployment from permanent contract jobs:

$$
\alpha_{w}^{P}\left[1-F_{P}\left(x_{O P}^{*}\right)\right] u=\lambda_{P} F_{P}\left(x_{I P}^{*}\right) e_{P}
$$

and (2) the flow out of unemployment into jobs with temporary contracts is equal to the reverse flow:

$$
\alpha_{w}^{T}\left[1-F_{T}\left(x_{T}^{*}\right)\right] u=\lambda_{T}\left(1-u-e_{P}\right)
$$

Combining the last two equations and using the fact that $e_{P}+e_{T}+u=1$ makes it possible to find expressions for the unemployment rate (the Beveridge curve) and the employment rates in temporary and permanent contract jobs:

$$
\begin{aligned}
u & =\frac{\lambda_{T} \lambda_{P} F_{P}\left(x_{I P}^{*}\right)}{\alpha_{w}^{P}\left[1-F_{P}\left(x_{O P}^{*}\right)\right] \lambda_{T}+\alpha_{w}^{T}\left[1-F_{T}\left(x_{T}^{*}\right)\right] \lambda_{P} F_{P}\left(x_{I P}^{*}\right)+\lambda_{T} \lambda_{P} F_{P}\left(x_{I P}^{*}\right)} \\
e_{P} & =\frac{\lambda_{T} \alpha_{w}^{P}\left[1-F_{P}\left(x_{O P}^{*}\right)\right]}{\alpha_{w}^{P}\left[1-F_{P}\left(x_{O P}^{*}\right)\right] \lambda_{T}+\alpha_{w}^{T}\left[1-F_{T}\left(x_{T}^{*}\right)\right] \lambda_{P} F_{P}\left(x_{I P}^{*}\right)+\lambda_{T} \lambda_{P} F_{P}\left(x_{I P}^{*}\right)} \\
e_{T} & =\frac{\alpha_{w}^{T}\left[1-F_{T}\left(x_{T}^{*}\right)\right] \lambda_{P} F_{P}\left(x_{I P}^{*}\right)}{\alpha_{w}^{P}\left[1-F_{P}\left(x_{O P}^{*}\right)\right] \lambda_{T}+\alpha_{w}^{T}\left[1-F_{T}\left(x_{T}^{*}\right)\right] \lambda_{P} F_{P}\left(x_{I P}^{*}\right)+\lambda_{T} \lambda_{P} F_{P}\left(x_{I P}^{*}\right)}
\end{aligned}
$$

The next step in finding the equilibrium is defining how wages are determined. Since workers and employers meet on a bilateral basis, wages are determined in a bargaining process between both parties once the match-specific productivity is realized. As is a common practice in the literature, the generalized axiomatic Nash bilateral bargaining outcome is used to determine wages (Mortensen and Pissarides, 1999a). If $\beta_{P}$ and $\beta_{T}$ are the worker's relative bargaining power parameters when he faces an employer offering a permanent and a temporary contract, respectively, the different wage rates solve the following optimization problems (according to the type of contract and if the worker 
is an outsider or an insider $)^{12}$ :

$$
\begin{aligned}
& \max _{\left\{w_{O P}(x)\right\}}\left(W_{O P}(x)-U\right)^{\beta_{P}}\left(J_{O P}(x)-V_{P}\right)^{1-\beta_{P}} \\
& \max _{\left\{w_{I P}(x)\right\}}\left(W_{I P}(x)-U\right)^{\beta_{P}}\left(J_{I P}(x)-V_{P}+\Psi\right)^{1-\beta_{P}} \\
& \max _{\left\{w_{T}(x)\right\}}\left(W_{T}(x)-U\right)^{\beta_{T}}\left(J_{T}(x)-V_{T}\right)^{1-\beta_{T}}
\end{aligned}
$$

From the worker's point of view, the threat point is simply the value of breaking the contract, which is the value of unemployment. From the firm's point of view, the threat point is the value of continued search, and it differs depending on the type of contract and whether the worker is an outsider or an insider. If an unemployed worker meets a firm with a permanent contract (the worker becomes a new hire or an outsider if the job is formed), then the threat point in the bargaining process is the value of an unfilled vacancy $\left(V_{P}\right)$ since the firm does not have to pay the severance tax if the worker is not hired. On the other hand, if a firm is bargaining the wage with a continuing permanent contract employee (an insider), then the threat point is $V_{P}-\Psi$ because if the worker is dismissed the firm ends up with an unfilled vacancy and the obligation to pay the severance tax. Finally, if an unemployed worker meets a firm with a temporary contract, the threat point is simply the value of an unfilled vacancy for this type of contract $\left(V_{T}\right)$. The total surplus from a match for $i=O P, I P, T\left(S_{i}(x)\right)$ is defined as the sum of the values to the firm and the worker net of their values of continued search and payroll taxes. Therefore:

$$
\begin{aligned}
S_{O P}(x) & =\left(W_{O P}(x)-U\right)+\frac{\left(1-\tau_{P}\right)}{\left(1+\phi_{P}\right)}\left(J_{O P}(x)-V_{P}\right) \\
S_{I P}(x) & =\left(W_{I P}(x)-U\right)+\frac{\left(1-\tau_{P}\right)}{\left(1+\phi_{P}\right)}\left(J_{I P}(x)-V_{P}+\Psi\right) \\
S_{T}(x) & =\left(W_{T}(x)-U\right)+\frac{\left(1-\tau_{T}\right)}{\left(1+\phi_{T}\right)}\left(J_{T}(x)-V_{T}\right)
\end{aligned}
$$

The solutions of the above optimization problems split the total surplus in fixed proportions at all points in time and at all $x \geq x_{i}^{*}$ for $i=O P, I P, T$. In each case, the proportions of the total surplus that goes to the workers are:

$$
\begin{aligned}
W_{O P}(x)-U & =\beta_{P} S_{O P}(x) \\
W_{I P}(x)-U & =\beta_{P} S_{I P}(x) \\
W_{T}(x)-U & =\beta_{T} S_{T}(x)
\end{aligned}
$$

\footnotetext{
${ }^{12}$ Wages are bargained when an unemployed worker meets a firm (outsider permanent or temporary) and when a shock arrives (insider permanent).
} 
while the firms obtain:

$$
\begin{aligned}
J_{O P}(x)-V_{P} & =\left(1-\beta_{P}\right) \frac{\left(1+\phi_{P}\right)}{\left(1-\tau_{P}\right)} S_{O P}(x) \\
J_{I P}(x)-V_{P}+\Psi & =\left(1-\beta_{P}\right) \frac{\left(1+\phi_{P}\right)}{\left(1-\tau_{P}\right)} S_{I P}(x) \\
J_{T}(x)-V_{P} & =\left(1-\beta_{T}\right) \frac{\left(1+\phi_{T}\right)}{\left(1-\tau_{T}\right)} S_{T}(x)
\end{aligned}
$$

Using equations (13) and (14) to rewrite the flow values of workers and firms, equations (1) to (7), in terms of the total surplus, and making the appropriate substitutions, it is easy to show that the wage equations are:

$$
\begin{aligned}
w_{O P}(x) & =\frac{\beta_{P}\left(x-\lambda_{P} \Psi\right)+\left(1-\beta_{P}\right) \frac{\left(1+\phi_{P}\right)}{\left(1-\tau_{P}\right)} r U}{\left(1+\phi_{P}\right)} \\
w_{I P}(x) & =\frac{\beta_{P}(x+r \Psi)+\left(1-\beta_{P}\right) \frac{\left(1+\phi_{P}\right)}{\left(1-\tau_{P}\right)} r U}{\left(1+\phi_{P}\right)} \\
w_{T}(x) & =\frac{\beta_{T} x+\left(1-\beta_{T}\right) \frac{\left(1+\phi_{T}\right)}{\left(1-\tau_{T}\right)} r U}{\left(1+\phi_{T}\right)}
\end{aligned}
$$

These wage equations are very similar to those found by Albrecht et al. (2009). The only difference is that, in this paper, workers also pay payroll taxes. In all cases, the wage is a weighted average of the match-specific productivity (adjusted by the severance tax in the case of permanent workers) and the worker's continuation value. Since $w_{O P}(x)=w_{I P}(x)-\frac{\beta_{P}\left(\lambda_{P}+r\right)}{\left(1+\phi_{P}\right)} \Psi$ and given that $\left(r, \lambda_{P}, \beta_{P}, \Psi\right)$ are all positive and $0 \leq \phi_{P} \leq 1$, the wage of a continuing employee (insider) with a permanent contract is higher than that earned by a new hire (outsider) with a similar type of contract (that is, $w_{I P}(x)>w_{O P}(x)$ ). This reflects the fact that a continuing employee has a better bargaining position with respect to the firm than a new hire because of the severance $\operatorname{tax}^{13}$.

Once again, using the workers' and firms' flow values written in terms of the total surpluses it is straightforward to verify that:

$$
\begin{aligned}
S_{O P}(x) & =\frac{x-x_{O P}^{*}}{r+\lambda_{P}} \frac{\left(1-\tau_{P}\right)}{\left(1+\phi_{P}\right)} \\
S_{I P}(x) & =\frac{x-x_{I P}^{*}}{r+\lambda_{P}} \frac{\left(1-\tau_{P}\right)}{\left(1+\phi_{P}\right)} \\
S_{T}(x) & =\frac{x-x_{T}^{*}}{r+\lambda_{T}} \frac{\left(1-\tau_{T}\right)}{\left(1+\phi_{T}\right)}
\end{aligned}
$$

\footnotetext{
${ }^{13}$ For a detailed discussion see Pissarides (2000), chapter 9.
} 
At this point, a discussion on the optimality of the match formation decision rule, which has a reservation value property, is necessary. So far it is assumed that in the model this decision rule is optimal. It is evident from equations (18) and (13), that both the total surplus function and the value of employment are strictly increasing in productivity $x$. Since the value of unemployment is constant, there is a reservation productivity $x_{i}^{*}$ such that $W_{i}(x)=U$, for $i=O P, I P, T$. Moreover, at that productivity the total surplus is zero $\left(S\left(x_{i}^{*}\right)=0\right)^{14}$. Using the flow values for an insider worker with a permanent contract, the wage equation, the total surplus definitions, and the condition $S\left(x_{I P}^{*}\right)=0$, it is possible to verify that:

$$
x_{I P}^{*}=\frac{\left(1+\phi_{P}\right)}{\left(1-\tau_{P}\right)} r U-r \Psi-\frac{\lambda_{P}}{r+\lambda_{P}} \int_{x_{I P}^{*}}^{\infty}\left(x^{\prime}-x_{I P}^{*}\right) f_{P}\left(x^{\prime}\right) d x^{\prime}
$$

Define $T\left(x_{I P}^{*}\right)$ equal to the left hand side of equation (19). Note that $T: \mathbb{R} \rightarrow \mathbb{R}$ and that it is differentiable. The function $T\left(x_{I P}^{*}\right)$ is a contraction on $\mathbb{R}$ with respect to the usual metric if there is a real number $\pi \leq 1$ such that the derivative $\left|T^{\prime}\left(x_{I P}^{*}\right)\right|<\pi$ for all $x_{I P}^{*} \in \mathbb{R}$. Note that $T^{\prime}\left(x_{I P}^{*}\right)=\frac{\lambda_{P}}{r+\lambda_{P}}\left(1-F_{P}\left(x_{I P}^{*}\right)\right)<\pi \leq 1$ if $r+\lambda_{P} F_{P}\left(x_{I P}^{*}\right)>0$, which is true given the possible values of the model parameters. The direct application of the contraction mapping theorem implies that the equation $x_{I P}^{*}=T\left(x_{I P}^{*}\right)$ has a unique solution in $\mathbb{R}^{15}$.

In the same way, the flow value of an outsider permanent worker, the wage equation, the definition of total surplus, and the condition $S\left(x_{O P}^{*}\right)=0$ can be used to find an expression for the reservation productivity of this type of worker. Additionally, equation (19) can assist in writing the resulting expression as:

$$
x_{O P}^{*}=x_{I P}^{*}+\left(\lambda_{P}+r\right) \Psi
$$

Note that $x_{O P}^{*} \geq x_{I P}^{*}$, which once again reflects the better bargaining position of the insider worker. Also, since $x_{I P}^{*}$ is uniquely determined, so is $x_{O P}^{*}$. Finally, the flow values of temporary contracts and the wage equation, together with the definition of the total surplus and the condition $S\left(x_{T}^{*}\right)=0$, generate:

$$
x_{T}^{*}=\frac{\left(1+\phi_{T}\right)}{\left(1-\tau_{T}\right)} r U
$$

\footnotetext{
${ }^{14}$ In the case of the permanent contracts, for which the termination is endogenous, this reservation productivity is also the destruction threshold.

${ }^{15}$ Note that the solution is unique given that the value of $r U$ is a function of the endogenous variables $q$ and $\eta$ (as mentioned in the next subsection)
} 
The reservation productivity for a temporary contract is equal to the flow value of the unemployment state (adjusted for payroll taxes), which is the usual result when the model has exogenous destruction and when there is no severance tax.

To close the model, the free-entry condition in the vacancy creation problem for both types of contracts is used. Profit maximization requires that all rents from new job creations should be exhausted such that the value of one more vacancy is zero, that is $V_{i}=0$ for $i=O P, T$ (Mortensen and Pissarides, 1994). Applying this condition to equations (8) and (9) and the definitions of total surplus in equation (18), the following equations can be obtained:

$$
\begin{aligned}
& k_{P}=\frac{m[\eta q]}{\eta q} \frac{\left(1-\beta_{P}\right)}{\left(r+\lambda_{P}\right)} \int_{x_{O P}^{*}}^{\infty}\left(x-x_{O P}^{*}\right) f_{P}(x) d x \\
& k_{T}=\frac{m[(1-\eta) q]}{(1-\eta) q} \frac{\left(1-\beta_{T}\right)}{\left(r+\lambda_{T}\right)} \int_{x_{T}^{*}}^{\infty}\left(x-x_{T}^{*}\right) f_{T}(x) d x
\end{aligned}
$$

which implicitly defines a system of equations in $q$ and $\eta$. These last two expressions and the definition of the total surplus can be used to rewrite the flow value of unemployment in equation (1) in the following way:

$$
r U=b+\left(\frac{1-\tau_{P}}{1+\phi_{P}}\right) \frac{\eta q \beta_{P} k_{P}}{\left(1-\beta_{P}\right)}+\left(\frac{1-\tau_{T}}{1+\phi_{T}}\right) \frac{(1-\eta) q \beta_{T} k_{T}}{\left(1-\beta_{T}\right)}
$$

A formal definition of the steady-state equilibrium can now be stated ${ }^{16}$ :

Definition 1 Given a vector of parameters $\left(b, \lambda_{P}, \lambda_{T}, r, \beta_{P}, \beta_{T}, k_{P}, k_{T}\right)$, a matching function $m(\cdot)$, a vector of taxes $\left(\tau_{P}, \tau_{T}, \phi_{P}, \phi_{T}, \Psi\right)$, and probability distribution functions for the productivity of permanent and temporary contracts $F_{P}(x)$ and $F_{T}(x)$, a steady-state equilibrium in a dual labor market economy is a labor market tightness $q$ and a proportion of job vacancies with permanent contracts $\eta$, together with reservation productivities $x_{i}^{*}$ for $i=O P, I P, T$, unemployment rate $u$ and employment rates $e_{P}$ and $e_{T}$ such that:

1. Given $q$ and $\eta$, and $r U$ from equation (24), the reservation productivities $x_{i}^{*}$ for $i=O P, I P, T$ solve equations (19) to (21).

2. Given the reservation productivities $x_{i}^{*}$ for $i=O P, I P, T$, the unemployment rate $u$ and employment rates $e_{P}$ and $e_{T}$ satisfy equations (10) to (12).

\footnotetext{
${ }^{16}$ The algorithm to computationally implement the model comes directly from the definition of steady-state equilibrium.
} 
3. $q$ and $\eta$ solve the system of equations (22) to (23) and are consistent with the reservation productivities $x_{i}^{*}$ for $i=O P, T$.

The equilibrium exists if the system of equations (22) to (23) has a solution for $q$ and $\eta$ in the third part of Definition 1, which in turn depends entirely on the matching function (recall that $x_{i}^{*}$ for $i=O P, I P, T$ is given in this stage). Under the assumptions made for the matching function, particularly the one on its increasing characteristic, there is a solution possibly involving a corner solution in $\eta$. If, in addition, it is assumed that the matching function is strictly increasing, then that solution is unique.

\section{Data}

To estimate the model, this paper uses microdata on the Chilean labor market, particularly, the longitudinal Social Protection Survey (Encuesta de Protección Social or EPS) from the Subsecretaría de Previsión Social ${ }^{17}$. This survey, which interviewed persons over the age of 18 years in 2002, 2004, 2006 and 2009, builds a panel of labor histories. In each survey, interviewers explicitly asked about the events (states in the labor market, monthly wages and weekly hours worked in each job) occurring in the years after the last survey in which the individual participated. A feature that makes this survey very attractive is its longitudinal dimension, one that is not commonly found in Latin American countries' datasets. Even though the model to be estimated does not have on-the-job search, which makes the data on labor market histories in the employment state less relevant, the longitudinal dimension provides valuable information on transitions from the unemployment state to temporary and permanent contract jobs, which is central for the identification strategy used in the next section.

The estimation of the search model considers the survey of $2006^{18}$. The last spells of surveys 2004 and 2002 where used to reduce (or eliminate) the number of left censored spells. Since the model assumes ex-ante homogeneous workers, some observed heterogeneity controls are necessary to guarantee a certain degree of homogeneity consistent with the model assumptions. In particular, the estimation sample satisfies the following criteria: males between the ages of 25 and 55

\footnotetext{
${ }^{17}$ The survey is conducted by the Microdata Center of the Economics Department at the University of Chile with the participation of academics of the University of Pennsylvania and the University of Michigan.

${ }^{18}$ The 2009 survey is contaminated with the recent recession, which started in 2008.
} 
years participating actively in the labor market and without college degree. Initially, there were 16,443 individuals in the 2006 survey and only 4,487 had these characteristics. The literature that estimates a search model, without on the job search, usually uses cross-section samples of workers in employment and unemployment states (Eckstein and van den Berg, 2007). Therefore, following this literature, a cross-section sample comprised of all labor market states (unemployment and employment spells) prevailing in January 2006 was constructed, and the transitions to temporary and permanent contract jobs were recorded for each unemployment event. All 4,487 of the initial group of persons had spells that continue into 2006 .

The sample size was further reduced due to other problems with the data. First, double censored spells (or very long spells) in the unemployment state cannot be used because they generate an identification problem as discussed in the next section ${ }^{19}$. Fortunately, this type of spell represented only $0.4 \%$ of the valid sample, and could be discarded. Second, the sample contained unrealistically high wages. Therefore, to avoid this outlier problem, 2.5 of the upper and lower percentiles in wages were dropped from the sample (resulting in a reduction of $13 \%$ of the valid sample observations). This elimination generated an average wage that is comparable with another Chilean Household Survey $^{20}$. Finally, the unemployment state is characterized only by persons who are looking for a job, because the model does not have data on participation decisions. To control for inconsistencies in the histories with respect to unemployment and inactivity, the survey questions the individuals on their labor market status, as well as whether they were looking for a job if in the last spell they considered themselves as unemployed. Using this data, inconsistencies in terms of unemployment and observations in which persons were not looking for a job were discarded. Finally, individuals with missing information on wages, hours worked or event dates were eliminated from the sample. These inconsistencies and missing data generates a further decrease of $6 \%$ and leaves the estimation sample with a total of 3,600 individuals.

Table 1 reports descriptive statistics of the sample. In the top panel, hourly wages are measured in U.S. dollars of 2004. They are calculated using reported weekly hours worked and monthly wages, which are expressed in 2004 prices using the CPI and converted to U.S. dollars using the average

\footnotetext{
${ }^{19}$ The estimations use only unemployment spells with durations less than 50 months. Eliminating some unemployment information does not affect the sample representativity because the proportion of unemployed individuals remains close to that reported in the CASEN 2006.

${ }^{20}$ CASEN 2006.
} 
exchange rate for that year. In the sample, there are 2,540 workers with permanent contracts and 861 with temporary contracts for whom there is valid information on wages. It is observed that, on average, workers with permanent contracts earn almost $59 \%$ more than workers with temporary contracts. Duration in each state, which is presented in the second panel of Table 1, is measured in months. The sample contains 199 unemployed individuals, who have been unemployed for 1.1 years, on average $^{21}$.

While $22.1 \%$ of all unemployment spells are right censored, none are left censored. Note that the majority of the spells are complete. As expected, permanent jobs last, on average, 3.5 times longer than temporary jobs. In both types of jobs the employment durations show a censoring problem at the beginning of the sample (left) and at the end of the time span (right). In the case of permanent contract jobs, left censored spells do not represent an important proportion of all spells. The third panel of Table 1 shows the percentage of unemployment spells that have transitioned from this state to each type of job. From all unemployment spells, there is information on the transitions to permanent and temporary contract jobs for 47 (representing 23.6\%) and 108 (representing 54.2\%) individuals, respectively. The remaining unemployment spells are right censored for which there is no information regarding transitions. Finally, the bottom panel shows that there is a greater share of permanent job contracts in the sample ${ }^{22}$.

Payroll tax and severance tax parameters are not estimated. Instead, these parameters are obtained from the labor legislation and the existing literature. The payroll taxes can be divided into two groups: social security contributions and unemployment insurance. Income taxes are not included in the value of payroll taxes because jobs under temporary and permanent contracts are formal jobs and pay equal income taxes. Social security contributions comprise $20 \%$ of wages ( $10 \%$ goes towards retirement, $7 \%$ towards health and approximately $3 \%$ towards disability) and are paid entirely by

\footnotetext{
${ }^{21}$ This average unemployment duration is high when compared to that of the 2006 CASEN survey, in which the average unemployment duration is only 2.7 months. It is well known that one of the most important problems encountered when working with self-reported data is the quality of the information, where short lived events tend to be over reported. The problem is exacerbated when the self-reported data is retrospective as is the case in the EPS. However, given its longitudinal dimension, which is central for the identification of the parameters, this paper uses the EPS, even though the CASEN has a bigger sample size and is more accurate (it is self-reported, but not retrospective).

${ }^{22}$ The low percent of temporary contracts underestimates the importance of temporary workers when compared with that of the 2006 CASEN survey (Table 1).
} 
the worker (Edwards and Edwards, 2000). On the other hand, the unemployment insurance contribution depends on who pays the tax. In particular, workers hired under permanent contracts pay $0.6 \%$ of their wages to the unemployment insurance, while employers contribute $1.6 \%$ towards this insurance. If a worker is hired under a temporary contract, only the employer contributes $3 \%$ of the wages towards unemployment insurance (Fajnzylber et al., 2009).

Finally, the EPS survey contains information on the reasons for job termination and whether a severance payment occurred or not. Therefore, in principle it is possible to calculate the severance payment. However, since information on wages and duration are required ${ }^{23}$, and durations are likely to be (left-) censored, the average firing cost is going to be underestimated. In addition, there are other firing costs that are not considered in the data. Hence, in this paper the firing cost is expressed in terms of the average wage of permanent contract jobs, that is, $\Psi=\Gamma \bar{w}$, where an estimate of $\Gamma$ is obtained from external sources. The World Bank (Doing Business Project) estimates a firing cost of 52 weeks for Chile $(\Gamma \simeq 12 \text { months })^{24}$, which is in line with the ones used in the literature for Latin American countries; for example, Bosch and Esteban-Pretel (2012) use a proportion of 15 months of average wages of formal jobs in the case of Brazil.

\section{Estimation}

The model is estimated by maximum log-likelihood method using supply side information of the labor market, that is, durations in different labor market states and wages under temporary and permanent contracts. While this information, as pointed out by Flinn (2006), is useful in learning about arrival and termination rates, and the parameters that characterize the productivity distribution, it is not useful in characterizing the vacancy creation problem. Hence, the lack of demand side information is clearly a limitation. Since the market tightness $(q)$ and the proportion of vacancies with permanent contracts $(\eta)$ affect only the arrival rates $\alpha_{w}^{P}$ and $\alpha_{w}^{T}$, it is possible to estimate them as parameters, after which $q$ and $\eta$ can be recovered by relying on other sources of information or by making

\footnotetext{
${ }^{23}$ If the contract lasts for more than 1 year and the employer dismisses the worker for economic reasons, he must provide the worker with a severance payment of one wage per year of work for up to 11 payments (Código del Trabajo, Gobierno de Chile).

${ }^{24}$ This firing cost includes the cost of advanced notice requirements, severance payments, and penalties due when terminating a redundant worker.
} 
specific assumptions regarding the matching function. Consequently, the vacancy cost parameters can also be estimated. This is one of the alternative identification strategies proposed by Flinn (2006) to estimate search and matching models with endogenous arrival rates only with supply side information. The identification of arrival and termination rates and productivity distribution parameters relies on Flinn and Heckman (1982), and since the model differentiates between insider and outsider permanent workers, a feature that is unobserved in the data, the estimation also relies on Flabbi (2010) strategy to identify a mixture of distributions.

\subsection{The likelihood Function}

The data consists of unemployment durations, hourly wages and durations in jobs with temporary and permanent contracts, and transitions from unemployment to both types of jobs, that is:

$$
\left(\left\{t_{i, u}, I_{i}\left(u \rightarrow e_{P}\right), I_{i}\left(u \rightarrow e_{T}\right)\right\}_{i \in U},\left\{w_{i, P}, t_{i, e_{P}}\right\}_{i \in E_{P}},\left\{w_{i, T}, t_{i, e_{T}}\right\}_{i \in E_{T}}\right)
$$

To find the unemployment duration contribution to the likelihood function, the hazard rate out of unemployment is defined as:

$$
h_{u}=\alpha_{w}^{P}\left[1-F\left(x_{O P}^{*}\right)\right]+\alpha_{w}^{T}\left[1-F\left(x_{T}^{*}\right)\right]
$$

In other words, the hazard rate is defined as the probability that a job is created once a worker meets an employer with any type of contract (reflected as a productivity drawn from the match greater than the reservation productivity). The hazard rate, conditional on the model, is constant. This implies that the contribution of the unemployment duration is the density of a negative exponential random variable with a coefficient equal to the hazard rate (Flabbi, 2010). Given that the unemployment duration is observed only for workers who are currently unemployed, the contribution of unemployment duration has to be weighted by the probability of being unemployed (the unemployment rate):

$$
\begin{aligned}
f_{u}\left(t_{i, u}, i \in U\right) & =f_{u}\left(t_{i, u} \mid i \in U\right) \operatorname{Pr}(i \in U) \\
& =h_{u} \exp \left(-h_{u} t_{u}\right) u \quad t_{u}>0
\end{aligned}
$$

Using the idea of multiple-exit duration models of Bover and Gómez (2004), it is possible to distinguish between exits from unemployment to a permanent job and to a temporary job. Let the 
indicator variables of exit to permanent and temporary employments be denoted by $D_{P}=I\left(u \rightarrow e_{P}\right)$ and $D_{T}=I\left(u \rightarrow e_{T}\right)$, respectively. Then, it is possible to define the following hazard rates:

$$
\begin{aligned}
h_{u}^{P} & =\alpha_{w}^{P}\left[1-F\left(x_{O P}^{*}\right)\right] \\
h_{u}^{T} & =\alpha_{w}^{T}\left[1-F\left(x_{T}^{*}\right)\right]
\end{aligned}
$$

such that the hazard rate out of unemployment is $h_{u}=h_{u}^{P}+h_{u}^{T}$. Therefore, the contribution of unemployment duration to the likelihood function becomes:

$$
f_{u}\left(t_{i, u}, i \in U\right)=\left[h_{u}^{P} \exp \left(-h_{u}^{P} t_{u}\right)\right]^{D_{P}}\left[h_{u}^{T} \exp \left(-h_{u}^{T} t_{u}\right)\right]^{D_{T}} u \quad t_{u}>0
$$

There are three features of the data that need to be considered in order to derive the contribution of wages to the likelihood function. First of all, wages are observed in the data, but productivity is not. Secondly, observed wages are accepted wages. Finally, this information is available only for currently employed workers. Therefore, and following Flabbi (2010), the first step in finding the wages contribution is to map the unconditional wage cumulative distribution from the unconditional productivity cumulative distribution, and construct the truncated version of the density of the former distribution taking into account the optimal decisions of the agent in the model (that is, the wage equations and reservation productivities). The second step is to find the corresponding wage density and weight it by the probability of being employed (the employment rate). The wages contribution to the likelihood function, conditional on being a newly hired worker (outsider) with a permanent contract, is ${ }^{25}$ :

$$
g\left(w_{i}, i \in E_{P} \mid w_{i}>w_{O P}\left(x_{O P}^{*}\right), O P\right)=\frac{\frac{\left(1+\phi_{P}\right)}{\beta_{P}} f_{P}\left(w_{i} \frac{\left(1+\phi_{P}\right)}{\beta_{P}}-\frac{\left(1-\beta_{P}\right)}{\beta_{P}} \frac{\left(1+\phi_{P}\right)}{\left(1-\tau_{P}\right)} r U+\lambda_{P} \Psi\right)}{1-F_{P}\left(x_{O P}^{*}\right)} e_{O P}
$$

On the other hand, the wages contribution to the likelihood function, conditional on being a continuing employee (insider) with a permanent contract, is:

$$
g\left(w_{i}, i \in E_{P} \mid w_{i}>w_{I P}\left(x_{I P}^{*}\right), I P\right)=\frac{\frac{\left(1+\phi_{P}\right)}{\beta_{P}} f_{P}\left(w_{i} \frac{\left(1+\phi_{P}\right)}{\beta_{P}}-\frac{\left(1-\beta_{P}\right)}{\beta_{P}} \frac{\left(1+\phi_{P}\right)}{\left(1-\tau_{P}\right)} r U-r \Psi\right)}{1-F_{P}\left(x_{I P}^{*}\right)} e_{I P}
$$

Equations (27) and (28) are conditioned on observing wages for new hires and for continuing employees, both under permanent contracts. However, information to identify the type of permanent

\footnotetext{
${ }^{25}$ The detailed derivations of the likelihood contributions are presented in a Technical Appendix (A1) available in https://sites.google.com/site/mauriciotejada/Research.
} 
worker is not available in the data. Therefore, one additional step in the construction of the likelihood contribution of wages is necessary for this type of contract. To remove the condition of whether the worker with a permanent contract is an outsider or an insider (considering that $w_{I P}\left(x_{I P}^{*}\right)=$ $\left.w_{O P}\left(x_{O P}^{*}\right)=w_{P}\left(x_{P}^{*}\right)\right)$, the following expression is used:

$$
\begin{aligned}
g\left(w_{i}, i \in E_{P} \mid w_{i}>w_{P}\left(x_{P}^{*}\right), P\right) & =g\left(w_{i}, i \in E \mid w_{i}>w_{P}\left(x_{P}^{*}\right), O P\right) \operatorname{Pr}(O P) \\
& +g\left(w_{i}, i \in E \mid w_{i}>w_{P}\left(x_{P}^{*}\right), I P\right) \operatorname{Pr}(I P)
\end{aligned}
$$

The probability of being a new hire (outsider) is $\operatorname{Pr}(O P)$, and it depends on the duration of the job since the worker remains an outsider if there are no productivity shocks, but the longer the contract lasts the more likely it is for productivity shocks to arrive. Productivity shocks, conditional on the model, are governed by a Poisson process. Therefore, $\operatorname{Pr}(O P)=\operatorname{Pr}[$ receive 0 shocks in $t]=\exp \left(-\lambda_{P} t_{e_{P}}\right)$. Also note that $\operatorname{Pr}(I P)=1-\operatorname{Pr}(O P)$. Using these probabilities, the last equation becomes:

$$
\begin{aligned}
g\left(w_{i}, i \in\right. & \left.E_{P} \mid w_{i}>w_{P}\left(x_{P}^{*}\right), P, t_{i, e_{P}}\right)= \\
& {\left[\frac{\exp \left(-\lambda_{P} t_{i, e_{P}}\right) \frac{\left(1+\phi_{P}\right)}{\beta_{P}} f_{P}\left(w_{i} \frac{\left(1+\phi_{P}\right)}{\beta_{P}}-\frac{\left(1-\beta_{P}\right)}{\beta_{P}} \frac{\left(1+\phi_{P}\right)}{\left(1-\tau_{P}\right)} r U+\lambda_{P} \Psi\right)}{1-G\left(w_{P}\left(x^{*}{ }_{P}\right) \mid P, O P\right)}\right.} \\
& \left.+\frac{\left(1-\exp \left(-\lambda_{P} t_{i, e_{P}}\right)\right) \frac{\left(1+\phi_{P}\right)}{\beta_{P}} f_{P}\left(w_{i} \frac{\left(1+\phi_{P}\right)}{\beta_{P}}-\frac{\left(1-\beta_{P}\right)}{\beta_{P}} \frac{\left(1+\phi_{P}\right)}{\left(1-\tau_{P}\right)} r U-r \Psi\right)}{1-G\left(w_{P}\left(x^{*}\right) \mid P, I P\right)}\right] e_{P}
\end{aligned}
$$

which is a mixture of two truncated distributions with a weight equal to the probability of being an outsider worker. The construction of the likelihood contribution of wages, conditional on being a temporary worker, follows the procedure described above and can be written as:

$$
g\left(w_{i}, i \in E_{T} \mid w_{i}>w_{T}\left(x_{T}^{*}\right), T\right)=\frac{\frac{\left(1+\phi_{T}\right)}{\beta_{T}} f_{T}\left(w_{i} \frac{\left(1+\phi_{T}\right)}{\beta_{T}}-\frac{\left(1-\beta_{T}\right)}{\beta_{T}} \frac{\left(1+\phi_{T}\right)}{\left(1-\tau_{T}\right)} r U\right)}{1-F_{P}\left(x_{T}^{*}\right)} e_{T}
$$

Using the densities in equations (26), (29), and (30), the likelihood function is:

$$
\begin{aligned}
L\left(\Theta^{L} ; w, t\right)= & \prod_{i=1}^{N}\left[f_{u}\left(t_{i, u}, i \in U\right)\right]^{u_{i}} \\
& \times\left[g\left(w_{i}, i \in E_{P} \mid w_{i}>w_{P}\left(x_{P}^{*}\right), P, t_{i, e_{P}}\right)\right]^{e_{i, P} \times\left(1-u_{i}\right)} \\
& \times\left[g\left(w_{i}, i \in E_{T} \mid w_{i}>w_{T}\left(x_{T}^{*}\right), T\right)\right]^{\left(1-e_{i, P}\right) \times\left(1-u_{i}\right)}
\end{aligned}
$$

where $\Theta^{L}$ is the vector of parameters, $t_{i, u}, w_{i}, t_{i, e_{P}}$ are unemployment duration, wages and employment duration under permanent contracts, respectively, $u_{i}=1$ if unemployed and 0 otherwise, 
and $e_{i, P}=1$ if the individual is employed with a permanent contract and 0 otherwise. Note that the employment duration of a job with a permanent contract indirectly contributes to the likelihood function, through the wage contributions, and that employment duration under temporary contracts does not provide useful information to the likelihood.

The reservation productivities are endogenous variables in the model and in order to choose the vector of parameters $\Theta^{L}$, the likelihood in equation (31) has to be maximized subject to the following equilibrium conditions:

$$
\begin{aligned}
x_{I P}^{*} & =\frac{\left(1+\phi_{P}\right)}{\left(1-\tau_{P}\right)} r U-r \Psi-\frac{\lambda_{P}}{r+\lambda_{P}} \int_{x_{I P}^{*}}^{\infty}\left(x^{\prime}-x_{I P}^{*}\right) f_{P}\left(x^{\prime}\right) d x^{\prime} \\
x_{O P}^{*} & =x_{I P}^{*}+\left(\lambda_{P}+r\right) \Psi \\
x_{T}^{*} & =\frac{\left(1+\phi_{T}\right)}{\left(1-\tau_{T}\right)} r U
\end{aligned}
$$

Finally, $r U$ is also an endogenous variable in the model, but for estimation purposes it is treated as a constant ${ }^{26}$. Therefore, $b$, which is the only parameter that does not appear directly in the likelihood, is chosen so that all equilibrium conditions are met as described below.

\subsection{Identification}

The identification strategy has three stages. The first follows Flinn and Heckman (1982) and Flabbi (2010) and is related to the identification of the parameters in the likelihood function (equation $31)$, which are the job arrival rates $\left(\alpha_{w}^{P}, \alpha_{w}^{T}\right)$, the productivity and termination shock arrival rates $\left(\lambda_{P}, \lambda_{T}\right)$, the reservation productivities $\left(x_{O P}^{*}, x_{I P}^{*}, x_{T}^{*}\right)$, the flow value of unemployment $(r U)$, and the parameters governing the productivity distributions $\left(F_{P}(x), F_{T}(x)\right) .{ }^{27}$

Following Flinn and Heckman (1982), a necessary condition for the identification of the parameters in the likelihood function is the recoverability condition of the productivity distribution. Under this condition, the entire wage distribution, and thereby the productivity distribution, should be uniquely recoverable from a truncated distribution with a known truncation point. On the other hand, according to Flabbi (2010) the necessary condition to identify a mixture of two truncated distributions, such as the likelihood contribution of permanent workers, discussed in the previous subsection, is that the productivity distribution belongs to a location-scale family. In this paper, it is

\footnotetext{
${ }^{26}$ This is a common practice in the literature, see, for example, Eckstein and van den Berg (2007).

${ }^{27}$ The formal proof of identification for the first stage of the strategy is presented in a Technical Appendix (A2) available in https://sites.google.com/site/mauriciotejada/Research.
} 
assumed that the match-specific productivity in both types of contracts is log-normally distributed with mean $\mu_{x}^{i}$ and standard deviation $\sigma_{x}^{i}$ for $i=P, T$, that is:

$$
F_{i}(x)=\Phi\left(\frac{\ln (x)-\mu_{x}^{i}}{\sigma_{x}^{i}}\right) ; \quad i=P, T
$$

where $\Phi$ is the standard normal cumulative distribution function. The log-normal distribution meets the recoverability condition (Eckstein and van den Berg, 2007) and belongs to a log location-scale family where $\mu_{x}^{i}$ is the location parameter and $\sigma_{x}^{i}$ is the scale parameter (Flabbi, 2010; Flinn, 2006).

Given the assumed match-specific productivity distributions, the identification of all the parameters in the likelihood rely on information regarding the transitions from unemployment to both types of jobs, the steady state equilibrium conditions (equations 10 to 12), the equilibrium conditions that determine reservation productivities (equations 19 to 21), the differences between wage distributions of permanent and temporary contract jobs (their location and scale parameters), and the differences between the wage distributions of permanent contract jobs with different tenures (their location and scale parameters). In the case of the Chilean labor market, Figures 2 and 3 show that the differences, by type of contract and by tenure, are important and can be exploited in the estimation.

Two parameters of the model, $\beta$ and $r$, are not estimated but are set exogenously. As pointed out by Eckstein and Wolpin (1995) and Flinn (2006) the Nash bargaining coefficient $\beta$ is difficult to identify without demand side information. This paper does not attempt to identify this parameter, instead it is assumed that $\beta_{P}=\beta_{T}=\beta=0.5$. The equal bargaining power assumption between workers with permanent and temporary contracts, $\beta_{P}=\beta_{T}$, can be justified by the non discrimination principle mentioned in Cahuc and Postel-Vinay (2002); and $\beta=0.5$, which is the common solution in the applied literature, arises when the discount rate is the same for workers and firms (Binmore et al., 1986; Binmore, 1978) ${ }^{28}$. On the other hand, although $r$ enters the likelihood function directly and not only through $r U$, it is not possible to identify all other parameters if this parameter is included in the estimation. Therefore, as is frequently done in applied micro-studies, $r$ is also set exogenously (Eckstein and van den Berg, 2007). In the particular case of Chile, $r$ is defined as $0.0053^{29}$.

The second stage follows Flinn (2006) and is related to the identification of the demand side parameters, which in the case of this model consists of the matching function, $m(\cdot)$, and the cost of

\footnotetext{
${ }^{28}$ Cited in Flabbi (2010).

${ }^{29}$ This rate represents $6.5 \%$ in annualized terms (see, for example, Fuenzalida and Mongrut, 2010).
} 
posting vacancies, $\left(k_{P}, k_{T}\right)$. Without directly available information about vacancies, $v_{P}$ and $v_{T}$, any additional parameters in the matching function $m(\cdot)$ cannot be identified. This is a important result since knowledge of the $m(\cdot)$ function is sufficient to identify the cost of the vacancy parameters, $k_{P}$ and $k_{T}$.

There are two alternative ways to identify the matching function. One relies on specific assumptions on its functional form and the other relies on the value of any additional parameters in the function. The first, proposed by Flinn (2006), consists in using a matching function that does not contain any unknown parameters. A good option, which fulfills the assumptions made in section 2, is the exponential matching function $m(u, v)=v\left(1-e^{-u / v}\right)^{30}$. The second consists in using external sources to obtain estimates of a Cobb-Douglas matching function parameter ${ }^{31}$. For the case of the Chilean labor market, the elasticity of the matching function was estimated using the procedure proposed by Borowczyk-Martins et al. (2013), and time series on vacancies, unemployment and arrival rate of jobs. ${ }^{32}$ The resulting matching function is: $m(u, v)=u^{0.1745} v^{0.8255}$. In any case, once the matching function is identified, all demand side parameters are identified.

Identification and (consistent) estimation of the parameters $q, \eta, k_{P}, k_{T}$ and $b$ build on the consistent estimators of the parameters $\alpha_{w}^{P}, \alpha_{w}^{T}, x_{O P}^{*}, \lambda_{P}, \lambda_{T}, r, x_{I P}^{*}, x_{T}^{*}$ in the following way. First, $\eta$ and $q$ solve $\widehat{\alpha}_{w}^{P}=m[\eta q]$ and $\widehat{\alpha}_{w}^{T}=m[(1-\eta) q]$ provided that the matching function $m(\cdot)$ is identified.

\footnotetext{
${ }^{30}$ This matching function can be justified by the presence of coordination failures in the labor market. However, despite its theoretical justification, this matching function generates implausible level and duration of unemployment for which it is, empirically, not a good approximation (Petrongolo and Pissarides, 2001).

${ }^{31}$ This alternative is attractive because the Cobb-Douglas matching function with constant returns to scale has had empirical success (Petrongolo and Pissarides, 2001). The drawbacks are the lack of micro-foundation of this matching function and the use of external estimates.

${ }^{32}$ In the estimation, quarterly observations of the job finding rate and the labor market tightness, for the $1992-2008$ period, was used. The former was calculated using the Chilean National Employment Survey (ENE) and following the methodology proposed by Shimer (2012). The labor market tightness was calculated using data on unemployed workers (also available in the ENE survey) and the vacancies index published by the Central Bank of Chile. The base model is $f_{t}=a_{t}+\gamma q_{t}$, where $f_{t}$ is the logarithm of the arrival rate, $q_{t}$ is the logarithm of the market tightness, $a_{t}$ is the logarithm of the level parameter of the matching function, and $\gamma$ is the parameter of interest. As in Borowczyk-Martins et al. (2013) it is assumed that the $a_{t}$ follows $a_{t}=\mu+\varepsilon_{t}$ with $\varepsilon_{t}=\sum_{i=1}^{p} \rho_{i} \varepsilon_{t-i}+\sum_{j=1}^{q} \theta_{j} \omega_{t-j}$. Using the last expression and the matching function, the estimation equation is $f_{t}=v+\sum_{i=1}^{p} \rho_{i} f_{t-i}+\gamma q_{t}+\sum_{i=1}^{p} \lambda_{i} q_{t-i}+\sum_{j=1}^{q} \theta_{j} \omega_{t-j}$ with $v=\left(1-\sum_{i=1}^{p} \rho_{i}\right) \mu$. Using statistical significance of the parameters and the information criteria the chosen model was $p=2$ and $q=2$.
} 
Second $k_{P}$ and $k_{T}$ solve:

$$
\begin{aligned}
& k_{P}=\frac{m[\widehat{\eta} \widehat{q}]}{\widehat{\eta} \hat{q}} \frac{\left(1-\beta_{P}\right)}{\left(r+\widehat{\lambda}_{P}\right)} \int_{\widehat{x}_{O P}^{*}}^{\infty}\left(x-\widehat{x}_{O P}^{*}\right) f_{P}(x) d x \\
& k_{T}=\frac{m[(1-\widehat{\eta}) \widehat{q}]}{(1-\widehat{\eta}) \widehat{q}} \frac{\left(1-\beta_{T}\right)}{\left(r+\widehat{\lambda}_{T}\right)} \int_{\widehat{x}_{T}^{*}}^{\infty}\left(x-\widehat{x}_{T}^{*}\right) f_{T}(x) d x
\end{aligned}
$$

Finally, once all the above parameters are identified, $b$ can be recovered using the equilibrium condition:

$$
b=\widehat{r U}-\left(\frac{1-\tau_{P}}{1+\phi_{P}}\right) \frac{\widehat{\eta} \widehat{q} \beta_{P} \widehat{k}_{P}}{\left(1-\beta_{P}\right)}-\left(\frac{1-\tau_{T}}{1+\phi_{T}}\right) \frac{(1-\widehat{\eta}) \widehat{q} \beta_{T} \widehat{k}_{T}}{\left(1-\beta_{T}\right)}
$$

\subsection{Econometric Issues}

Three econometric issues arise in estimating the model: (1) measurement error in wages, (2) censoring in unemployment duration data, and (3) censoring in employment duration data. This subsection explains how each of these issues are dealt with.

Measurement error in wages is incorporated in the estimation procedure for two reasons. First, it is very likely that wages are measured with error since the wage data is self reported and it includes wages from past years ${ }^{33}$. Second, and most important, it is not possible to estimate the reservation productivities using the lowest observed wage in both types of contracts, in the spirit of Flinn and Heckman (1982), because the mapping between the reservation productivity and the reservation wage, in the case of permanent jobs, depends on other parameters to be estimated (the relations are implied in the equilibrium conditions). This problem is critical because the reservation productivities are the truncation parameters in the accepted wage distributions. Therefore, changing these parameters in the maximization process of the likelihood function changes its support, which violates one of the regularity conditions ${ }^{34}$. A way to avoid this problem is to introduce measurement error. Following Flinn (2002) and Flabbi and Leonardi (2010), it is assumed that the measurement error is multiplicative:

$$
w^{o}=w \cdot \varepsilon
$$

and log-normally distributed, therefore:

$$
m(\varepsilon)=\phi\left(\frac{\ln (\varepsilon)-\mu_{\varepsilon}}{\sigma_{\varepsilon}}\right) \frac{1}{\varepsilon \sigma_{\varepsilon}} \quad \varepsilon>0
$$

\footnotetext{
${ }^{33} \mathrm{As}$ is common in the literature, it is assumed that measurement error is present in wages data but not in duration data (Eckstein and van den Berg, 2007; Flinn, 2006).

${ }^{34}$ See Flinn and Heckman (1982) for a complete discussion.
} 
In order to restrict the number of parameters to estimate, it is assumed that the conditional expectation of the observed wages is equal to the true wages, as is done in Flinn (2002); that is, $E\left[w^{o} \mid w\right]=w$, which implies that $E[\varepsilon \mid w]=1$. This assumption together with the log-normality assumption implies that the parameters $\mu_{\varepsilon}$ and $\sigma_{\varepsilon}$ satisfy $\sigma_{\varepsilon}=\sqrt{-2 \mu_{\varepsilon}}$. Therefore, only one parameter of the measurement error distribution has to be estimated.

Given the wage density functions for jobs with permanent and temporary contracts, $g\left(w_{i}, i \in\right.$ $\left.E_{P} \mid w_{i}>w_{P}\left(x_{P}^{*}\right), P\right)$ and $g\left(w_{i}, i \in E_{T} \mid w_{i}>w_{T}\left(x_{T}^{*}\right), T\right)$, respectively, and the error density function $m(\varepsilon)$, the implied density functions of observed wages can be written as:

$$
\begin{aligned}
g_{w^{o}}^{P}\left(w_{i}^{o}\right) & =\int_{w_{P}\left(x_{P}^{*}\right)} \frac{1}{w_{i}} m\left(\frac{w_{i}^{o}}{w_{i}}\right) g\left(w_{i}, i \in E_{P} \mid w_{i}>w_{P}\left(x_{P}^{*}\right), P\right) d w_{i} \\
g_{w^{o}}^{T}\left(w_{i}^{o}\right) & =\int_{w_{T}\left(x_{T}^{*}\right)} \frac{1}{w_{i}} m\left(\frac{w_{i}^{o}}{w_{i}}\right) g\left(w_{i}, i \in E_{T} \mid w_{i}>w_{T}\left(x_{T}^{*}\right), T\right) d w_{i}
\end{aligned}
$$

Censoring in unemployment duration data is potentially very problematic because it can generate identification problems and bias the estimated parameters. In particular, if the unemployment spells are double censored, that is right and left censored at the same time, the identification of the parameters in the likelihood estimation is not possible because permanent unemployment can be generated by a different combination of the parameters (Flinn, 2002). For this reason, double censored spells are not used in the estimation. The estimated parameters will be biased when there are right or left censored spells. Fortunately, controlling for these two types of censoring is straightforward when the spells are exponentially distributed, and can easily be incorporated in the likelihood function. Because there are no left censored unemployment spells in the sample, this article only describes right censoring correction. Let $c_{i}^{r}$ be indicator variables taking the value of 1 if the unemployment spell is right censored and zero otherwise. The likelihood contribution of a complete unemployment spell is

$$
f_{u}\left(t_{i, u}, i \in U, c_{i}^{l}=0, c_{i}^{r}=0\right)=h_{u} \exp \left(-h_{u} t_{u}\right) u \quad t_{u}>0
$$

while the likelihood contribution of a right censored unemployment spell is:

$$
f_{u}\left(t_{i, u}, i \in U, c_{i}^{r}=1\right)=\operatorname{Pr}\left[T>t_{u}\right]=\exp \left(-h_{u} t_{u}\right) u \quad t_{u}>0
$$

Taking into account measurement error in wages and censoring in unemployment spells, the likeli- 
hood function becomes:

$$
\begin{aligned}
L\left(\Theta^{L} ; w, t\right)= & \prod_{i=1}^{N}\left[f_{u}\left(t_{i, u}, i \in U, c_{i}^{l}=0, c_{i}^{r}=0\right)\right]^{u \times\left(1-c_{i}^{r}\right)} \\
& \times\left[f_{u}\left(t_{i, u}, i \in U, c_{i}^{r}=1\right)\right]^{u \times c_{i}^{r}} \\
& \times\left[\int_{w_{P}\left(x_{P}^{*}\right)} \frac{1}{w_{i}} m\left(\frac{w_{i}^{o}}{w_{i}}\right) g\left(w_{i}, i \in E_{P} \mid w_{i}>w_{P}\left(x_{P}^{*}\right), P\right) d w_{i}\right]^{e_{P} \times(1-u)} \\
& \times\left[\int_{w_{T}\left(x_{T}^{*}\right)} \frac{1}{w_{i}} m\left(\frac{w_{i}^{o}}{w_{i}}\right) g\left(w_{i}, i \in E_{T} \mid w_{i}>w_{T}\left(x_{T}^{*}\right), T\right) d w_{i}\right]^{\left(1-e_{p}\right) \times(1-u)}
\end{aligned}
$$

which is maximized to choose $\Theta^{L}$, subject to equilibrium constraints:

$$
\begin{aligned}
x_{I P}^{*} & =\frac{\left(1+\phi_{P}\right)}{\left(1-\tau_{P}\right)} r U-r \Psi-\frac{\lambda_{P}}{r+\lambda_{P}} \int_{x_{I P}^{*}}^{\infty}\left(x^{\prime}-x_{I P}^{*}\right) f_{P}\left(x^{\prime}\right) d x^{\prime} \\
x_{O P}^{*} & =x_{I P}^{*}+\left(\lambda_{P}+r\right) \Psi \\
x_{T}^{*} & =\frac{\left(1+\phi_{T}\right)}{\left(1-\tau_{T}\right)} r U
\end{aligned}
$$

The last econometric issue is related to the censoring problem in the employment duration data. In this paper, only employment spells of jobs with permanent contracts are relevant. Recall that employment duration indirectly contributes to the likelihood function through the wage contribution, because it affects the probability of being an outsider (that is, $\operatorname{Pr}(O P)=\operatorname{Pr}$ [receive 0 shocks in $\left.t]=\exp \left(-\lambda_{P} t_{e_{P}}\right)\right)$. As previously mentioned, employment duration spells can be left or right censored. Right censored spells do not represent a problem because the probability of receiving a determined number of shocks before time $t$ is what is important in the model; hence, at that time the future is irrelevant. On the other hand, left censored spells do represent a potential problem. This can be observed by expressing the $\operatorname{Pr}[$ receive 0 shocks in $t$ ] such that the distinction is made between the observed duration $t_{e_{P}}^{o}$ and the true duration $t_{e_{P}}$. Since $t_{e_{P}}^{o}=t_{e_{P}}-a$, where $a \geq 0$, then:

$$
\begin{aligned}
\operatorname{Pr}(O P) & =\exp \left(-\lambda_{P}\left(t_{e_{P}}^{o}+a\right)\right) \\
& =\exp \left(-\lambda_{P} t_{e_{P}}^{o}\right) \exp \left(-\lambda_{P} a\right)
\end{aligned}
$$

Given that $\exp \left(-\lambda_{P} a\right) \leq 1$ with $\lambda_{P} \geq 0$ and $a \geq 0$, it is clear that if $a$ is not taken into account, then the probability of receiving 0 shocks in $t$ is overestimated. In the case of permanent contracts, this affects the weights in the mixture of wage densities, which in turn can potentially lead to a bias problem in the estimation. 
The censoring problem in the employment duration data is neglected in the estimation results presented in the next subsection since the probability of receiving zero shocks in $t$ decreases exponentially with employment duration. Hence, the effect of the additional months in the duration of long spells is not important. This is the case in the data used in the estimations, since the left censored spells duration is at least 17 months (and there are less than $2 \%$ of these spells).

\subsection{Estimation Results}

Table 2 reports the estimation results. The first two rows show the job arrival rates for both temporary and permanent jobs. Temporary jobs arrive $16 \%$ faster than permanent jobs. In particular, while offers with temporary contracts arrive approximately every four and a half months, offers with permanent contracts do so every five months. Rows five through seven of Table 2 report the estimated reservation productivities for permanent (insider and outsider) and temporary jobs. An insider permanent worker and a firm with a permanent contract are willing to continue with a contractual relation if the productivity is at least 1.15 U.S. dollars per hour, which is $20 \%$ less than the productivity required to form a match between an outsider permanent worker and a firm with a permanent contract (1.38 U.S. dollars per hour). This reflects the effect of the firing cost on the bargaining position of an insider worker. When workers going from unemployment to temporary and permanent jobs are compared, results on reservation productivity indicate that workers and firms are less stringent when agreeing on a temporary contract than when forming a permanent contractual agreement. In this case, the difference in the reservation productivity is $21 \%$. Combining job arrival rates and reservation productivities, the estimation results suggest that workers are, on average, unemployed for a total of 13 months (the hazard rate out of unemployment is 0.075 ). Table 4 reports the predictions of the model for these and other variables.

The productivity shock arrival rate for permanent jobs, reported in the third row of Table 2, indicates that productivity shocks do not occur very often. Similarly, the termination rate for the temporary jobs, reported in the fourth row of Table 2, also shows a high persistence. As a result, in both cases the hazard rates out of employment, shown in Table 4, are low. When comparing these hazard rates with their data counterparts, also shown in Table 4, it is clear that the shock arrival rate for permanent jobs and the termination rate for temporary jobs are underestimated, as are the correspondent hazard rates out of employment. However, it is important to note that 
the hazard rates observed in the data are not directly comparable with those of the model because, in the absence of on-the-job search, the interpretation of the employment duration in the model is career duration instead of job duration. Another explanation of these results is directly related with the data. As mentioned in section 3, the data on unemployment and employment duration has a retrospective and self-reported nature and seems to be over reported compared to another household survey. Since the model estimation strategy strongly relies on this duration data to estimate the arrival and the termination rates of jobs, as well as the arrival rate of shocks, an over reported unemployment duration generates high employment duration in order to be consistent with the steady state conditions of the model.

The estimated values for the location and the scale parameters of the log-normal match specific distributions for both types of jobs are shown in the last four rows of Table 2. These values imply (statistically) similar productivity, on average, for workers in temporary jobs. Also, there is six times more uncertainty at the moment of drawing a productivity from the match specific productivity of a permanent job, than from a match specific productivity of a temporary job. Table 4 reports the predictions for the average productivity and its variance and shows that workers receive wage offers that are, on average, $9 \%$ higher when they meet firms with permanent contracts than when they meet firms with temporary ones. Once the job is accepted that difference becomes $60 \%$, on average. Finally, the estimation of all parameters is quite precise when evaluating with the asymptotic standard errors.

Table 3 shows the estimated value of the technological parameters (the proportion of permanent vacancies, the market tightness and the flow cost of vacancies in temporary and permanent jobs) and the preference parameter (the flow value of leisure) using both the Cobb-Douglas and the Exponential matching functions. All the results discussed below are conditional on the particular assumptions made about the matching function. First, the proportion of permanent job vacancies in the market is around 45\%, regardless of the matching function used. Second, the estimated market tightness differ between matching functions. In particular, the market tightness, along with the unemployment rate in Table 4, imply that the total vacancy rate of the economy $\left(v_{P}+v_{T}\right)$ is $1.6 \%$ when the Cobb-Douglas function is used, and 2.2\% when the Exponential function is used. Third, under the Cobb-Douglas matching function, the flow costs of permanent and temporary jobs are around 33 and 9 U.S. dollars, respectively. Meanwhile, these same flow costs are around 23 and 7 
U.S. dollars under the Exponential matching function ${ }^{35}$. In any case, it is clear that maintaining a permanent job vacancy unfilled is substantially (between 3.2 and 3.6 times) more expensive than maintaining a temporary job vacancy unfilled. Finally, the flow disutility of leisure is around 4 U.S. dollars per hour and it does not depend on which matching function is used to identify it.

To conclude this section, some specification tests that were performed and an assessment of the fit of the model are discussed. The last two rows of the bottom panel of Table 2 report the statistics of two F-tests. The first test corresponds to the null hypothesis that both types of jobs have the same arrival rate, which implies that the proportion of vacancies is $50 \%$ for each type of job. This null hypothesis can be rejected at 5\% significance level. Using the asymptotic standard error of the arrival rates in Table 2, the hypothesis that the arrival rate of temporary jobs is equal to zero, implying that only permanent jobs survive, and the hypothesis that the arrival rate of permanent jobs is equal to zero, implying that only temporary jobs survive, can also be tested. The results indicate that both hypotheses are also rejected at $1 \%$ significance level. Therefore, in the Chilean labor market both types of vacancies, permanent and temporary, coexist but there is one that dominates. The second test tries to verify if the productivity in each type of job is drawn from the same distribution (given that in both cases log-normality is imposed). Once again, the data does not support the hypothesis (at 1\% significance level) that productivities in both types of jobs come from the same distribution.

Table 4 reports the predictions of the model and some comparable moments in the data. In terms of fit, the wages predicted by the model are slightly higher than its sample counterparts. On the other hand, model predictions of the unemployment and employment rates are really close to those observed in the data. The hazard rate out of unemployment also fits the data well. However, the model predictions of hazard rates out of employment do not fit the data well as was discussed before.

\footnotetext{
${ }^{35}$ Comparing this result with that found by Flinn (2002), who estimates a flow vacancy cost of 128 U.S. dollars for the U.S. economy for 1996, suggests that the cost of an unfilled vacancy of a permanent job is substantially lower in the Chilean labor market. However, the difference is not that significant, relative to the average wage (while in the U.S. economy it is 18 times the average wage, in Chile it is 13 times the average wage of a permanent worker).
} 


\section{Counterfactual and Policy Experiments}

The counterfactual experiment consists in comparing the benchmark economy, that is, the one characterized by the estimated parameters and in which temporary contracts are allowed, with an economy in which the use of temporary contracts is not allowed by law. In the latter economy, the model is solved assuming $\eta=1$ and using all other estimated parameters (except those related with temporary jobs). The policy experiment consists in analyzing the impact of changes in the firing cost on the two economies previously mentioned by taking into account the equilibrium effects. In particular, the experiment analyzes the effect of changes in the firing cost within a range of zero to twice the benchmark severance tax. In performing the counterfactual and policy experiments, a CobbDouglas matching function is used to solve the model with the estimated elasticity of $\gamma=0.8255$. In both exercises, it is possible to analyze the effect, under alternative institutional arrangements of more stringent labor protection, on labor market dynamics (that is market tightness, availability of vacancies of both types of jobs, arrival rates, hazard rates out of unemployment and employment, and unemployment and employment rates) and on productivity and wages (reservation productivities, average offered and accepted wages, and inequality between workers with different types of contracts).

\subsection{Labor Market Dynamics}

Table 5, first row, shows that at any firing cost, the labor market is tighter when temporary contracts are allowed. In particular, when these contracts are allowed, the market tightness is at least $50 \%$ higher than the market tightness when they are not allowed. This is explained by the fact that the presence of temporary contracts increases the vacancies available in the market. Analyzing the effect of an increase in the firing cost, the same table shows that the market tightness decreases with the firing cost when temporary contract jobs are not allowed because this cost makes vacancy creations of permanent jobs less attractive. Quantitatively, the effect is not substantial - going from no firing cost to twice the benchmark firing cost leads to a decrease of $1.6 \%$ in the market tightness. On the other hand, when temporary contracts are allowed, the effect of the firing cost on the market tightness is the opposite. Indeed, despite the fact that the firing cost makes permanent job vacancy creations less attractive, they make temporary job vacancy creations more attractive and in the end this latter 
effect dominates the former one. This is observed in the decreasing proportion of permanent job vacancies shown in the second row of Table 5. Market tightness increases by more than $8 \%$, going from no firing cost to twice the benchmark firing cost and the proportion of permanent vacancies decreases by almost 5 percentage points. Permanent vacancies can disappear if the firing cost is really high (more than 10 times that of the benchmark). This is possible in the model but not plausible in practice.

The arrival rates for permanent and temporary jobs, shown in the third and fourth rows of Table 5, reflect what was discussed above. When temporary jobs are allowed, as the firing cost increases, fewer vacancies for permanent jobs reduce the rate at which they arrive, while more temporary job vacancies accelerate their arrival rate. The reduction in the case of permanent job vacancies is $10.1 \%$ and the increase in the case of temporary job vacancies is $23.4 \%$. When temporary jobs are not allowed, the arrival rate of permanent jobs also slows with firing costs but the size of the effect is much smaller - it only reduces permanent job vacancies by $1.3 \%$.

Table 5, rows five to seven, show the effect of firing costs on the different labor market states, that is, on the unemployment and the employment rates, under both types of contracts and their corresponding durations. The fifth row shows shows that the unemployment rate falls with more stringent employment protection when temporary contracts are not allowed. This indicates that the effect of the firing cost in reducing the job destruction rate dominates the one that discourages employment creations. The hazard rate out of unemployment, shown in the eight row of Table 5, decreases suggesting that even though there are fewer unemployed workers, those who are unemployed stay in that state longer. However, the impact on the unemployment rate and its duration is quantitatively small - the unemployment rate only falls by 0.3 percentage points, going from zero protection to twice the benchmark firing cost and the workers stay unemployed only half a month longer. When temporary contracts are allowed, the effect of stringent protection on the unemployment rate is attenuated, indicating that the the effect of the flows out of temporary jobs dominate that of the flows out of unemployment into temporary contracts. The positive impact of temporary jobs is that they help to reduce unemployment duration by almost a month when employment protection becomes more stringent.

The sixth row of Table 5 shows that the employment rate in permanent jobs increases slightly (by less than half a percentage point). This is consistent with the decrease in the unemployment rate 
when temporary contracts are not allowed. However, the fact that the employment rate of permanent jobs falls by 6.2 percentage points when temporary contracts are allowed, implying a substitution between permanent and temporary jobs, is more interesting (recall that the unemployment rate is fairly constant in this scenario). The ninth row of Table 5 shows the hazard rate out of permanent jobs. As expected, more stringent protection in permanent jobs discourages its destruction and this is true regardless of whether the use of temporary contracts is allowed or not. Quantitatively, duration of permanent jobs increases by 6.8 and $10.4 \%$ when temporary contracts are allowed and when they are not, respectively. Finally, the seventh row of Table 5 shows that the employment rate in temporary jobs increases by 6 percentage points when the firing cost rises. This is consistent with the substitution effect previously mentioned. This positive relationship between temporary job shares and employment protection corresponds to the model counterpart of Figure 1. On the other hand, row tenth of Table 5 shows the hazard rate out of temporary jobs, which is constant by construction (the termination rate in the model is exogenous).

\subsection{Productivity and Wages}

Row eleventh of Table 5 shows how the reservation productivity of new hires with permanent contracts (outsiders) changes with the firing cost. Regardless of the existence of temporary contracts, the firing cost discourages new hires by increasing the threshold at which matches are formed. When temporary contracts are not allowed, this reservation productivity increases by less than $0.5 \%$ with the firing cost, while when both types of contracts coexist it increases by $4.3 \%$. The existence of temporary contracts exacerbates the negative effect on job creations. Row twelfth of Table 5 shows the reservation productivity of continuing employees with permanent contracts (insiders). In this case, the reservation productivity decreases with the firing cost and the effect is quantitatively important (it falls by more than 30\%). This is explained by the fact that more protection generates a higher bargaining advantage for workers, reducing the firms' outside option. Therefore, firms are willing to maintain a larger proportion of their workers even if they become less productive after a shock has occurred. For both, insiders and outsiders, the reservation productivity is always higher when temporary contracts are allowed, indicating that a higher productivity is sustained with permanent jobs when the two types of contracts coexist. Row thirteenth of Table 5 shows the reservation productivity of temporary jobs. The positive effect on unemployment of increasing the firing cost in 
permanent jobs is that the lower reservation productivity facilitates job creation. The down side is that lower productivity jobs will be created.

Rows fourteenth to sixteenth of Table 5 show the average accepted wages. In the case of permanent jobs, the firing cost affects average accepted wages through three mechanisms. First, they directly affect the total surplus of the match. Second, they have an equilibrium effect on the flow value of unemployment. Third, they have an equilibrium effect on the conditional average productivity through the reservation values. On the other hand, in the case of temporary jobs, average accepted wages are affected by the equilibrium effects on the flow value of unemployment and the reservation productivity. In that Table it is shown that the equilibrium effects of the firing cost on reservation productivities are important. Indeed, they almost offset the direct effect of the firing cost for new hires (the decrease is only between 1.3 and 4.4\%) and substantially reduce the average accepted wages for continuing employees (between 10.5 and 14.8\%). Row sixteenth shows a fall of $3.1 \%$ in average accepted wages for temporary jobs. Hence, the effect on the reservation productivity also contributes to this fall. Finally, accepted wages are higher when temporary jobs are allowed. This is due to a higher reservation productivity, in the case of average accepted wages.

This subsection concludes with the effect of the firing cost on inequality. In this paper, inequality is defined as the difference in wage rates of permanent and temporary workers. Therefore, in this exercise both types of contracts are allowed. Table 5, row eighteenth, shows the ratios between the average wage in temporary jobs and the average wage in permanent jobs for new hires and for continuing employees. There are three comments worth mentioning from the analysis of that ratio. First, inequality is high since the gap between accepted wages for permanent and temporary workers are around $40 \%$ (comparing new hires in temporary jobs and continuing employees in permanent jobs, respectively). Second, the pattern of the wage ratios is consistent with the changes in wages given by changes in the firing cost. Finally, although inequality changes with the firing cost, it remains high for the range of firing costs considered in this paper, suggesting that the effect of this policy is limited in this aspect.

\subsection{Welfare Analysis}

Following Flinn (2006) and Flabbi (2010), this paper exploits the stationary nature of the model to analyze the long-run welfare impact of changes in the policy parameters (mainly the firing cost) 
under the two different assumptions about the labor market institution: when temporary contracts are allowed and when they are not. To define a long-run measure of welfare, it is important to recall that at any point in time workers are unemployed, employed under a permanent contract or employed under a temporary contract. Similarly, at any point in time a firm can have a permanent or temporary job vacancies filled or they can be searching to fill their vacancies. The latter is not taken into account because unfilled vacancies have, by definition, a value of zero (free-entry condition). In this context, the following Social Welfare function is defined:

$$
\begin{aligned}
S(\tau, \phi, \Psi)= & u(\tau, \phi, \Psi) U_{u}(\tau, \phi, \Psi)+e_{O P}(\tau, \phi, \Psi)\left[\bar{W}_{O P}(\tau, \phi, \Psi)+\bar{J}_{O P}(\tau, \phi, \Psi)\right] \\
& +e_{I P}(\tau, \phi, \Psi)\left[\bar{W}_{I P}(\tau, \phi, \Psi)+\bar{J}_{I P}(\tau, \phi, \Psi)\right]+e_{T}\left[\bar{W}_{T}(\tau, \phi, \Psi)+\bar{J}_{T}(\tau, \phi, \Psi)\right]
\end{aligned}
$$

where: $\tau=\left(\tau_{P}, \tau_{T}\right), \phi=\left(\phi_{P}, \phi_{T}\right), U_{u}(\tau, \phi, \Psi)$ is the unemployed agents' welfare, $\bar{V}_{j}(\tau, \phi, \Psi)$ is the average workers' welfare $(j=O P, I P, T)$ and $\bar{J}_{j}(\tau, \phi, \Psi)$ is the average welfare of firms with filled vacancies $(j=O P, I P, T)$. Note also that $e_{O P}(\tau, \phi, \Psi)=e_{P}(\tau, \phi, \Psi) \operatorname{Pr}(O P)$ and $e_{I P}(\tau, \phi, \Psi)=e_{P}(\tau, \phi, \Psi)(1-\operatorname{Pr}(O P))$. To implement equation (32) it is necessary to define the individual contribution to the Social Welfare function:

$$
\begin{aligned}
U_{u}(\tau, \phi, \Psi) & =\int_{0}^{\min \left\{x_{I P}^{*}, x_{T}^{*}\right\}} U\left[\frac{f_{P}(x)}{F_{P}\left(x_{I P}^{*}\right)} I_{\left[x_{I P}^{*} \leq x_{T}^{*}\right]}+\frac{f_{T}(x)}{F_{T}\left(x_{T}^{*}\right)}\left(1-I_{\left[x_{I P}^{*} \leq x_{T}^{*}\right]}\right)\right] d x \\
\bar{W}_{j}(\tau, \phi, \Psi) & =\int_{x_{j}^{*}}^{\infty} W_{j}(x)\left[\frac{f_{P}(x)}{1-F_{P}\left(x_{j}^{*}\right)}\right] d x \quad j=I P, O P \\
\bar{W}_{T}(\tau, \phi, \Psi) & =\int_{x_{T}^{*}}^{\infty} W_{T}(x)\left[\frac{f_{T}(x)}{1-F_{T}\left(x_{T}^{*}\right)}\right] d x \\
\bar{J}_{j}(\tau, \phi, \Psi) & =\int_{x_{j}^{*}}^{\infty} J_{j}(x)\left[\frac{f_{P}(x)}{1-F_{P}\left(x_{j}^{*}\right)}\right] d x \quad j=I P, O P \\
\bar{J}_{T}(\tau, \phi, \Psi) & \left.=\int_{x_{T}^{*}}^{\infty} J_{T}(x)\right)\left[\frac{f_{T}(x)}{1-F_{T}\left(x_{T}^{*}\right)}\right] d x
\end{aligned}
$$

Equation (32) is then used to evaluate changes in welfare (total, workers' and firms' welfares) when the firing cost changes in the case where temporary contracts are allowed and in the case where they are not allowed. Note that equation (32) is the analog to the criterion used by Hosios (1990) in his labor market efficiency study when two types of jobs exist.

Figure 4 shows the ratio between the level of welfare reached when temporary contracts are not allowed and when they are allowed, for each degree of labor protection. Note that for any firing cost below 1.8 the benchmark firing cost the total welfare is greater in an economy without temporary 
contracts. The second observation that can be made is that the relative welfare decreases when the firing cost increases. When the firing cost is low, the level of welfare is higher in an economy without temporary contracts. In this case what matters is the possibility of productivity gains in permanent contracts. However, when firing costs are rather high, the level of welfare in an economy with both types of contracts increases (reducing the relative welfare) and the degree of flexibility becomes more valuable. Temporary contracts make agents better off only if the firing cost reaches high levels. Finally, the shape of the relative welfare means that stringent labor protection generates important trade offs in terms of productivity gains and flexibility.

\section{Concluding Remarks}

This paper presents a search and matching model with the following features: First, it has a dual labor market represented by two types of contracts, permanent and temporary, and the use of both is endogenously determined as part of the equilibrium. Second, labor protection is incorporated in the form of firing costs to analyze its relationship with the equilibrium share of temporary contracts. Finally, it incorporates the possibility of productivity gains in permanent jobs. This model is structurally estimated using likelihood methods for the Chilean labor market. In the estimation procedure only supply side data is used and the identification strategy, particularly for the technological or demand side parameters, is discussed. Finally, counterfactual and policy experiments are performed to quantitatively evaluate the role of labor protection legislation and the use of temporary contracts in unemployment, welfare, and inequality. Two main assumptions that depart from the literature are made. First, it is assumed that there are two types of jobs in the market, permanent and temporary; hence, there is also a productivity (and wage) distribution associated with each type of job. This assumption allows for the fitting of overlapping wage distributions. Second, temporary jobs have a predefined duration (possibly more than 12 months), are not subject to firing costs, and are not necessarily converted into a permanent job at the end of the contract.

The estimation results indicate that both temporary and permanent contracts survive in equilibrium, and $45 \%$ of the available vacancies are for permanent contracts. This reflects large differences in vacancy costs (US\$33 vs. US\$9). In terms of the dynamics of the labor market, the magnitude of the parameters suggests that temporary jobs arrive more frequently than permanent jobs $(16 \%$ 
faster) and that workers meeting both types of vacancies draw, on average, similar productivities. With respect to wages, workers receive wage offers that are, on average, $9 \%$ higher when they meet firms with permanent contracts than when they meet firms with temporary ones. Once the job is accepted that difference becomes $60 \%$, on average. Finally, the long run unemployment rate is about $5.2 \%$.

The counterfactual and policy experiments results indicate that when the costs of posting vacancies are different, temporary contracts survive even if there is no firing cost. Then, as the firing cost increases, fewer permanent job vacancies reduce the rate at which they arrive, while more temporary job vacancies accelerate its arrival rate. Temporary jobs magnify the effect of firing costs on permanent job arrival rates. Even though labor protection is useful in reducing unemployment, temporary contracts balance out this effect leaving unemployment practically unchanged. Meanwhile, labor protection increases the (equilibrium) employment rate in jobs with temporary contracts. The effects on employment and unemployment rates discussed above implies that there is a strong substitution effect between both types of jobs. With respect to inequality, the negative effect of firing costs on wages is barely compensated with the existence of temporary contracts. Hence, inequality is persistent. Finally, welfare analysis indicates that temporary contracts generate welfare gains only if labor protection is (implausibly) high.

Some policy implications can be drawn from these results. First, temporary contracts increase flexibility but they do not make agents better off. However, it is important to remember that this is a steady-state result, which does not take into account the cushion effect during business cycles. Second, limiting the use of temporary contracts (in an extreme case, eliminating them) can increase welfare only if labor protection is not stringent. Therefore, stringent labor protection generates important trade offs between productivity and flexibility. Hence, labor protection levels matter in terms of welfare. 


\section{References}

Aguirregabiria, Victor and Cesar Alonso-Borrego (2009), "Labor contracts and flexibility: Evidence from a labor market reform in spain." Working Papers tecipa-346, University of Toronto, Department of Economics.

Albrecht, James, Lucas Navarro, and Susan Vroman (2009), "The effects of labour market policies in an economy with an informal sector." Economic Journal, 119, 1105-1129.

Alvarez, Fernando and Marcelo Veracierto (2012), "Fixed-term employment contracts in an equilibrium search model." Journal of Economic Theory, 147, 1725 - 1753.

Bentolila, Samuel and Juan J. Dolado (1994), "Labour flexibility and wages: Lessons from spain." Economic Policy, 9, pp. 53-99.

Blanchard, Olivier and Augustin Landier (2002), "The perverse effects of partial labour market reform: fixed-term contracts in france." Economic Journal, 112, F214-F244.

Borowczyk-Martins, Daniel, Gregory Jolivet, and Fabien Postel-Vinay (2013), "Accounting for endogeneity in matching function estimation." Review of Economic Dynamics, 16, 440-451.

Bosch, Mariano and Julen Esteban-Pretel (2012), "Job creation and job destruction in the presence of informal markets." Journal of Development Economics, 98, 270-286.

Bosio, Giulio (2009), "Temporary employment and wage gap with permanent jobs: evidence from quantile regression." MPRA Paper 16055, University Library of Munich, Germany.

Bover, Olympia and Ramón Gómez (2004), "Another look at unemployment duration: exit to a permanent vs. a temporary job." Investigaciones Economicas, 28, 285-314.

Cahuc, Pierre and Fabien Postel-Vinay (2002), "Temporary jobs, employment protection and labor market performance." Labour Economics, 9, 63-91.

Cao, Shutao, Enchuan Shao, and Pedro Silos (2011), "Fixed-term and permanent employment contracts: Theory and evidence." Working Papers 11-21, Bank of Canada. 
Carpio, Susana, David Giuliodori, Graciana Rucci, and Rodolfo Stucchi (2011), "The effect of temporary contracts on human capital accumulation in chile." IDB Publications 35358, Inter-American Development Bank.

Dolado, Juan José and Rodolfo Stucchi (2008), "Do temporary contracts affect tfp? evidence from spanish manufacturing firms." IZA Discussion Papers 3832, Institute for the Study of Labor (IZA).

Eckstein, Zvi and Gerard J. van den Berg (2007), "Empirical labor search: A survey." Journal of Econometrics, 136, 531-564.

Eckstein, Zvi and Kenneth I Wolpin (1995), "Duration to first job and the return to schooling: Estimates from a search-matching model." Review of Economic Studies, 62, 263-86.

Edwards, Sebastian and Alejandra Cox Edwards (2000), "Economic reforms and labor markets: Policy issues and lessons from chile." NBER Working Papers 7646, National Bureau of Economic Research, Inc.

Fajnzylber, Eduardo, Cristóbal Huneeus, and Andrea Repetto (2009), "Workers choices in the chilean unemployment insurance system."

Felgueroso, Florentino and Sara De la Rica Goiricelaya (1999), "Wage differentials between permanent and temporal contracts: Further evidence." DFAEII Working Papers 2002-07, University of the Basque Country - Department of Foundations of Economic Analysis II.

Flabbi, Luca (2010), "Gender discrimination estimation in a search model with matching and bargaining." International Economic Review, 51, 745-783.

Flabbi, Luca and Marco Leonardi (2010), "Sources of earnings inequality: Estimates from an onthe-job search model of the us labor market." European Economic Review, 54, 832-854.

Flinn, C. and J. Heckman (1982), "New methods for analyzing structural models of labor force dynamics." Journal of Econometrics, 18, 115-168.

Flinn, Christopher J (2002), "Labour market structure and inequality: A comparison of italy and the u.s." Review of Economic Studies, 69, 611-45. 
Flinn, Christopher J. (2006), "Minimum wage effects on labor market outcomes under search, matching, and endogenous contact rates." Econometrica, 74, 1013-1062.

Fuenzalida, Darcy and Samuel Mongrut (2010), "Estimation of discount rates in latin america: Empirical evidence and challenges." Journal of Economics, Finance and Administrative Science, $15,7-44$.

Gobierno de Chile (2001), Código del Trabajo.

Güell, Maia (2003), "Fixed-term contracts and the duration distribution of unemployment." IZA Discussion Papers 791, Institute for the Study of Labor (IZA).

Harrison, Ann E and Edward Leamer (1997), "Labor markets in developing countries: An agenda for research." Journal of Labor Economics, 15, S1-19.

Heckman, James J. and Carmen Pages (2000), "The cost of job security regulation: Evidence from latin american labor markets." NBER Working Papers 7773, National Bureau of Economic Research, Inc.

Hosios, Arthur J (1990), "On the efficiency of matching and related models of search and unemployment." Review of Economic Studies, 57, 279-98.

Kalleberg, Arne L. (2000), "Nonstandard employment relations: Part-time, temporary and contract work." Annual Review of Sociology, 26, 341-365.

Macho-Stadler, Ines, David Perez-Castrillo, and Nicolás Porteiro (2011), "Optimal coexistence of long-term and short-term contracts in labor markets." Ufae and iae working papers, Unitat de Fonaments de l'Anàlisi Econòmica (UAB) and Institut d'Anàlisi Econòmica (CSIC).

Mortensen, Dale T and Christopher A Pissarides (1994), "Job creation and job destruction in the theory of unemployment." Review of Economic Studies, 61, 397-415.

Mortensen, Dale T. and Christopher A. Pissarides (1999a), "Job reallocation, employment fluctuations and unemployment." In Handbook of Macroeconomics (J. B. Taylor and M. Woodford, eds.), volume 1 of Handbook of Macroeconomics, chapter 18, 1171-1228, Elsevier. 
Mortensen, Dale T. and Christopher A. Pissarides (1999b), "New developments in models of search in the labor market." In Handbook of Labor Economics (O. Ashenfelter and D. Card, eds.), volume 3 of Handbook of Labor Economics, chapter 39, 2567-2627, Elsevier.

Paolini, Dimitri and Juan de Tena (2012), "Short or long-term contract? firm's optimal choice." Empirica, 39, 1-18.

Petrongolo, Barbara and Christopher A. Pissarides (2001), "Looking into the black box: A survey of the matching function." Journal of Economic Literature, 39, 390-431.

Pierre, Gaelle and Stefano Scarpetta (2004), "Employment regulations through the eyes of employers - do they matter and how do firms respond to them?" Policy Research Working Paper Series 3463, The World Bank.

Pissarides, Christopher A (2000), Equilibrium Unemployment Theory, 2nd edition. The MIT Press, Cambridge, MA.

Pissarides, Christopher A. (2001), "Employment protection." Labour Economics, 8, 131-159.

Puentes, Esteban and Dante Contreras (2009), "Informal jobs and contribution to social security: Evidence from a double selection model." Working Papers wp307, University of Chile, Department of Economics.

Shimer, Robert (2012), "Reassessing the ins and outs of unemployment." Review of Economic Dynamics, 15, 127-148.

Subsecretaría de Previsión Social (2002), "Social protection survey." available in www.proteccionsocial.cl.

Wasmer, Etienne (1999), "Competition for jobs in a growing economy and the emergence of dualism." Economic Journal, 109, 349-71.

World Bank (2005), Doing Bussines in 2006: Creating Jobs. Washingtin D.C. 
Table 1: Sample Descriptive Statistics

\begin{tabular}{|c|c|c|}
\hline & Mean & S.D. \\
\hline \multicolumn{3}{|c|}{ Wages (Dollars per Hour) } \\
\hline$w \mid e$ & 2.31 & 1.61 \\
\hline$w \mid e_{P}$ & 2.55 & 1.75 \\
\hline$w \mid e_{T}$ & 1.60 & 0.77 \\
\hline Ratio & 1.59 & \\
\hline \multicolumn{3}{|c|}{ Duration (Months) } \\
\hline$t \mid u$ & 13.33 & 11.02 \\
\hline$\%$ Left Censored & 0.00 & \\
\hline \% Right Censored & 22.11 & \\
\hline$t \mid e_{P}$ & 87.15 & 74.44 \\
\hline$\%$ Left Censored & 1.50 & \\
\hline$\%$ Right Censored & 86.54 & \\
\hline$t \mid e_{T}$ & 24.29 & 21.65 \\
\hline$\%$ Left Censored & 0.23 & \\
\hline$\%$ Right Censored & 64.23 & \\
\hline \multicolumn{3}{|c|}{ Transitions (Percent) } \\
\hline$u \rightarrow e_{P}$ & 23.62 & \\
\hline$u \rightarrow e_{T}$ & 54.27 & \\
\hline \multicolumn{3}{|c|}{ Share by Type of Contract (Percent) } \\
\hline Permanent & 74.68 & \\
\hline Temporary & 25.32 & \\
\hline
\end{tabular}

Sample: Men between 25 and 55 years old, and without college degree. 
Table 2: Estimated Parameters

\begin{tabular}{|c|c|c|}
\hline & Param. & Std.Err. $\left(^{*}\right)$ \\
\hline$\alpha_{w}^{P}$ & 0.1939 & 0.0011 \\
\hline$\alpha_{w}^{T}$ & 0.2273 & 0.0011 \\
\hline$\lambda_{P}$ & 0.0022 & 0.00002 \\
\hline$\lambda_{T}$ & 0.0107 & 0.00003 \\
\hline$x_{T}^{*}$ & 1.1499 & 0.0794 \\
\hline$x_{I P}^{*}$ & 1.1527 & 0.1077 \\
\hline$x_{O P}^{*}$ & 1.3831 & 0.1070 \\
\hline$r U$ & 1.1164 & 0.0771 \\
\hline$\sigma_{\epsilon}$ & 0.2752 & 0.0067 \\
\hline$\mu_{P}^{x}$ & -1.3995 & 0.0015 \\
\hline$\sigma_{P}^{x}$ & 1.5381 & 0.0087 \\
\hline$\mu_{T}^{x}$ & -0.5877 & 0.0012 \\
\hline$\sigma_{T}^{x}$ & 0.9286 & 0.0038 \\
\hline No. Obs. & \multicolumn{2}{|r|}{3,600} \\
\hline Loglik & \multicolumn{2}{|r|}{$-7,988$} \\
\hline F-test $\alpha_{w}^{P}=\alpha_{w}^{T}$ & \multicolumn{2}{|r|}{217} \\
\hline F-test $\mu_{P}^{x}=\mu_{T}^{x}$ & \multirow{2}{*}{\multicolumn{2}{|c|}{2,229}} \\
\hline$\sigma_{P}^{x}=\sigma_{T}^{x}$ & & \\
\hline
\end{tabular}

$\left.{ }^{*}\right)$ Asymptotic standard errors. 
Table 3: Technological and Preference Parameters

\begin{tabular}{lrr}
\hline \hline & Param. & \multicolumn{2}{c}{ Std.Err. } \\
\hline & Cobb Douglas Matching Function $(*)$ \\
\hline$\eta$ & 0.4521 & 0.0033 \\
$q$ & 0.3033 & 0.00002 \\
$k_{P}$ & 33.0946 & 2.1703 \\
$k_{T}$ & 9.7396 & 0.6242 \\
$b$ & -4.0007 & 0.4262 \\
\hline & Exponential Matching Function \\
\hline$\eta$ & 0.4586 & 0.0028 \\
$q$ & 0.4254 & 0.00002 \\
$k_{P}$ & 23.2585 & 1.5499 \\
$k_{T}$ & 7.0282 & 0.4452 \\
$b$ & -4.0007 & 0.4262 \\
\hline \hline
\end{tabular}

$\left(^{*}\right) \gamma=0.8255$.

Note: Standard Errors calculated using delta method. 
Table 4: Predicted Values

\begin{tabular}{|c|c|c|c|}
\hline & Value & Std.Err. $(*)$ & Data \\
\hline \multicolumn{4}{|c|}{ Productivity } \\
\hline$E\left(x_{P}\right)$ & 0.805 & 0.01200 & n.a. \\
\hline$V\left(x_{P}\right)$ & 6.259 & 0.37090 & n.a. \\
\hline$E\left(x_{T}\right)$ & 0.855 & 0.00200 & n.a. \\
\hline$V\left(x_{T}\right)$ & 1.001 & 0.01690 & n.a. \\
\hline \multicolumn{4}{|c|}{ Offered Wages } \\
\hline$E\left(w_{O P}\right)$ & 1.072 & 0.04290 & n.a. \\
\hline$E\left(w_{I P}\right)$ & 1.187 & 0.04260 & n.a. \\
\hline$E\left(w_{T}\right)$ & 0.986 & 0.03950 & n.a. \\
\hline \multicolumn{4}{|c|}{ Accepted Wages } \\
\hline$E\left(w_{O P} \mid e_{P}\right)$ & 2.700 & 0.13410 & 2.554 \\
\hline$E\left(w_{I P} \mid e_{P}\right)$ & 2.577 & 0.13940 & 2.554 \\
\hline$E\left(w_{T} \mid e_{T}\right)$ & 1.658 & 0.09560 & 1.604 \\
\hline \multicolumn{4}{|c|}{ Labor Market Status } \\
\hline$u$ & 0.052 & 0.00510 & 0.055 \\
\hline$e_{P}$ & 0.709 & 0.00710 & 0.706 \\
\hline$e_{T}$ & 0.239 & 0.00200 & 0.239 \\
\hline \multicolumn{4}{|c|}{ Labor Market Dynamics } \\
\hline$h_{u}$ & 0.075 & 0.00710 & 0.075 \\
\hline$h_{e_{P}}$ & 0.002 & 0.00002 & 0.012 \\
\hline$h_{e_{T}}$ & 0.011 & 0.00003 & 0.041 \\
\hline
\end{tabular}

(*) Standard Errors calculated using delta method. 
Table 5: Counterfactual and Policy Experiments

\begin{tabular}{|c|c|c|c|c|c|c|}
\hline & \multicolumn{3}{|c|}{ TC Allowed } & \multicolumn{3}{|c|}{ TC Not Allowed } \\
\hline & $0 \times \Psi$ & $1 \times \Psi$ & $2 \times \Psi$ & $0 \times \Psi$ & $1 \times \Psi$ & $2 \times \Psi$ \\
\hline \multicolumn{7}{|c|}{ Market Tightness } \\
\hline$q$ & 0.291 & 0.303 & 0.316 & 0.195 & 0.193 & 0.192 \\
\hline$\eta$ & 0.501 & 0.452 & 0.407 & 1.000 & 1.000 & 1.000 \\
\hline \multicolumn{7}{|c|}{ Arrival Rates } \\
\hline$\alpha_{w}^{P}$ & 0.204 & 0.194 & 0.184 & 0.259 & 0.258 & 0.256 \\
\hline$\alpha_{w}^{T}$ & 0.203 & 0.227 & 0.251 & n.a. & n.a. & n.a. \\
\hline \multicolumn{7}{|c|}{ Labor Market Status } \\
\hline$u$ & 0.052 & 0.052 & 0.052 & 0.046 & 0.045 & 0.043 \\
\hline$e_{P}$ & 0.741 & 0.709 & 0.679 & 0.954 & 0.955 & 0.957 \\
\hline$e_{T}$ & 0.207 & 0.239 & 0.270 & n.a. & n.a. & n.a. \\
\hline \multicolumn{7}{|c|}{ Hazard Rates } \\
\hline$h_{U}$ & 0.07005 & 0.07470 & 0.07951 & 0.03862 & 0.03824 & 0.03788 \\
\hline$h_{e_{P}}$ & 0.00191 & 0.00186 & 0.00179 & 0.00188 & 0.00181 & 0.00170 \\
\hline$h_{e_{T}}$ & 0.01069 & 0.01069 & 0.01069 & n.a. & n.a. & n.a. \\
\hline \multicolumn{7}{|c|}{ Reservation Productivity } \\
\hline$x_{O P}^{*}$ & 1.355 & 1.383 & 1.413 & 1.224 & 1.227 & 1.231 \\
\hline$x_{I P}^{*}$ & 1.355 & 1.153 & 0.953 & 1.224 & 0.997 & 0.770 \\
\hline$x_{T}^{*}$ & 1.175 & 1.150 & 1.128 & n.a. & n.a. & n.a. \\
\hline \multicolumn{7}{|c|}{ Accepted Wages } \\
\hline$E\left(w_{O P} \mid e_{P}\right)$ & 2.720 & 2.700 & 2.684 & 2.523 & 2.467 & 2.412 \\
\hline$E\left(w_{I P} \mid e_{P}\right)$ & 2.720 & 2.577 & 2.433 & 2.523 & 2.339 & 2.149 \\
\hline$E\left(w_{T} \mid e_{T}\right)$ & 1.687 & 1.658 & 1.633 & n.a. & n.a. & n.a. \\
\hline \multicolumn{7}{|c|}{ Inequality } \\
\hline Outsider/Insider & 1.000 & 1.048 & 1.103 & 1.000 & 1.054 & 1.122 \\
\hline Temporary/Outsider & 0.620 & 0.614 & 0.609 & n.a. & n.a. & n.a. \\
\hline Temporary/Insider & 0.620 & 0.644 & 0.671 & n.a. & n.a. & n.a. \\
\hline
\end{tabular}


Figure 1: Share of Temporary Jobs and Strictness of Protection for Regular Jobs

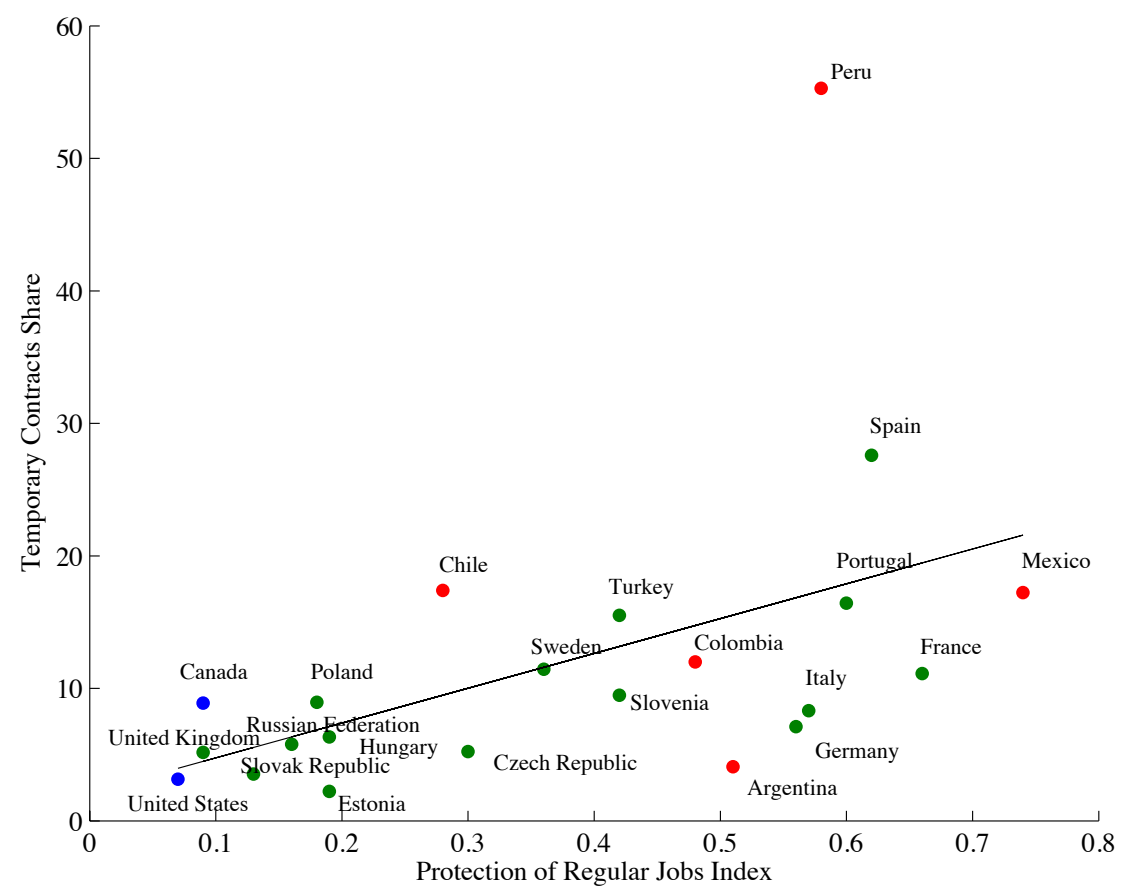

Sources: Pierre and Scarpetta (2004), Tokman and Martinez (1999), OECD Stats.

Figure 2: Sample Wages Densities by Type of Contract

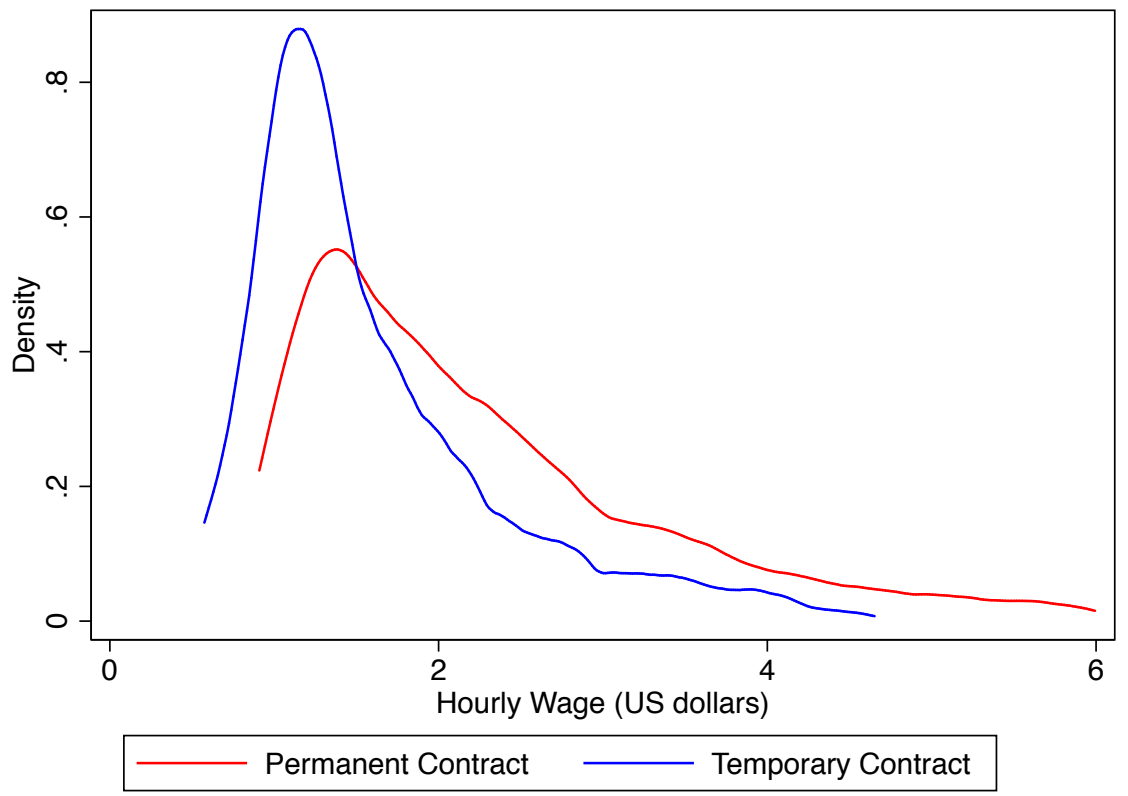


Figure 3: Sample Wages Densities for Permanent Contracts by Tenure

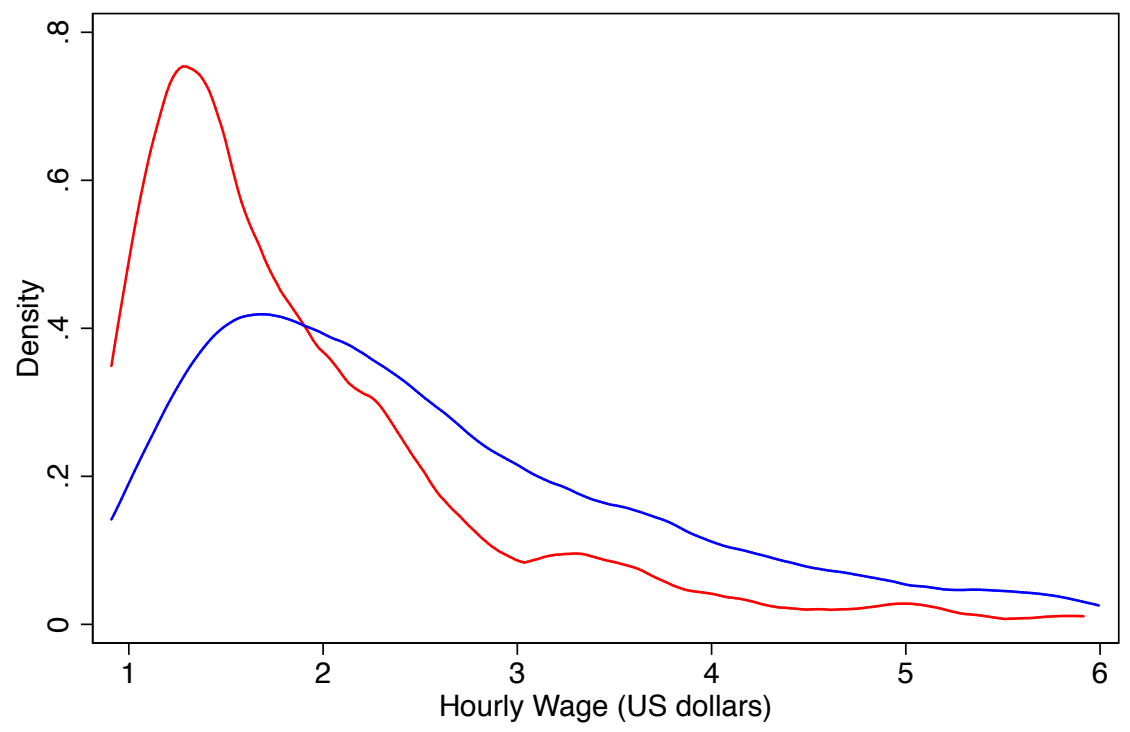

Less than a 2 Years of Tenure More than 5 Years of Tenure

Figure 4: Welfare Analysis

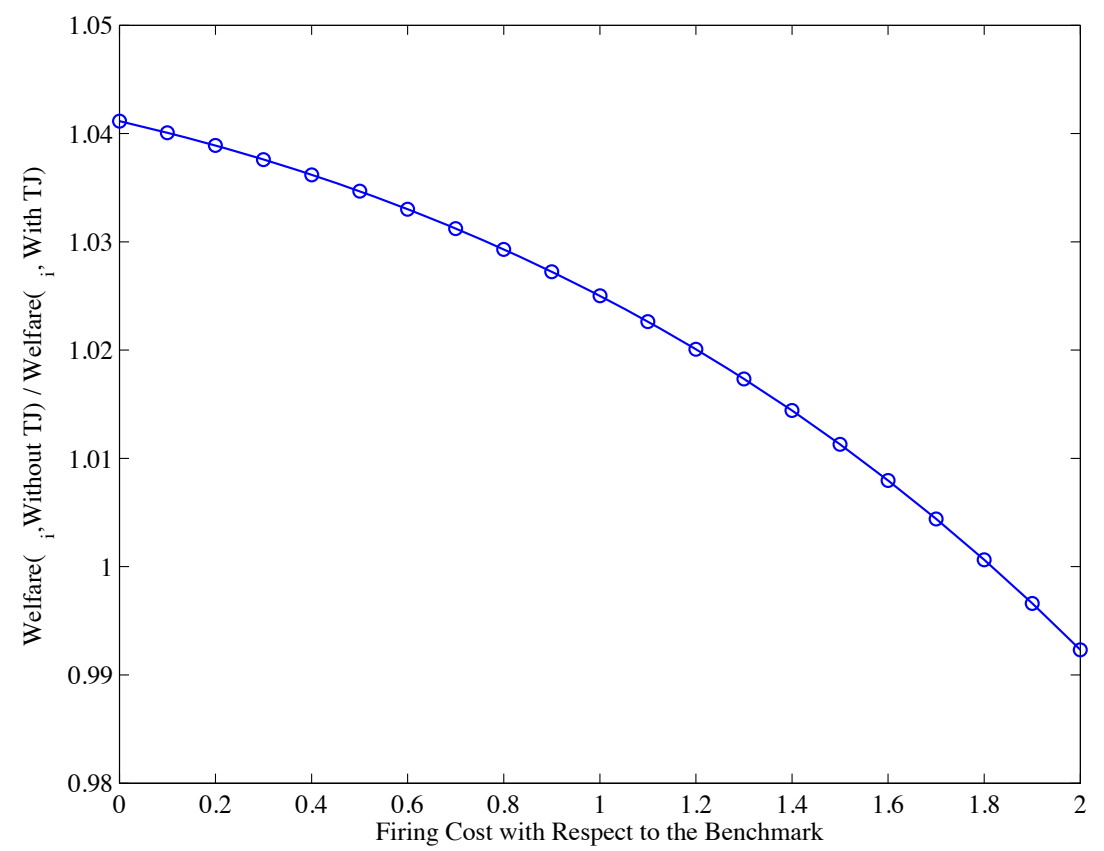

